\title{
Linking ENSO and heavy rainfall events over coastal British Columbia through a weather pattern classification
}

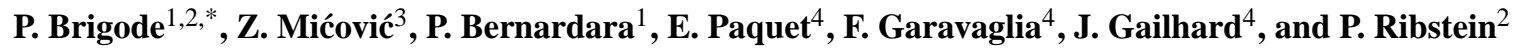 \\ ${ }^{1}$ LNHE, R\&D, Electricité de France, Chatou, France \\ ${ }^{2}$ UMR 7619 Sisyphe, Université Pierre et Marie Curie, Paris, France \\ ${ }^{3}$ BC Hydro, Engineering, Burnaby, BC, Canada \\ ${ }^{4}$ DTG, DMM, Electricité de France, Grenoble, France \\ * Invited contribution by P. Brigode, one of the EGU, Union Outstanding Student Poster (OSP) Award winners 2012.
}

Correspondence to: P. Brigode (pierre.brigode@edf.fr)

Received: 6 September 2012 - Published in Hydrol. Earth Syst. Sci. Discuss.: 15 October 2012

Revised: 15 March 2013 - Accepted: 26 March 2013 - Published: 17 April 2013

\begin{abstract}
Classifications of atmospheric weather patterns (WPs) are widely used for the description of the climate of a given region and are employed for many applications, such as weather forecasting, downscaling of global circulation model outputs and reconstruction of past climates. WP classifications were recently used to improve the statistical characterisation of heavy rainfall. In this context, bottom-up approaches, combining spatial distribution of heavy rainfall observations and geopotential height fields have been used to define WP classifications relevant for heavy rainfall statistical analysis. The definition of WPs at the synoptic scale creates an interesting variable which could be used as a link between the global scale of climate signals and the local scale of precipitation station measurements. We introduce here a new WP classification centred on the British Columbia (BC) coastal region (Canada) and based on a bottom-up approach. Five contrasted WPs composed this classification, four rainy WPs and one non-rainy WP, the anticyclonic pattern. The four rainy WPs are mainly observed in the winter months (October to March), which is the period of heavy precipitation events in coastal $\mathrm{BC}$ and is thus consistent with the local climatology. The combination of this WP classification with the seasonal description of rainfall is shown to be useful for splitting observed precipitation series into more homogeneous sub-samples (i.e. sub-samples constituted by days having similar atmospheric circulation patterns) and thus identifying, for each station, the synoptic situations that generate the highest hazard in terms of heavy rainfall events. El NiñoSouthern Oscillations (ENSO) significantly influence the fre-
\end{abstract}

quency of occurrence of two coastal BC WPs. Within each WP, ENSO seem to influence only the frequency of rainy events and not the magnitudes of heavy rainfall events. Consequently, heavy rainfall estimations do not show significant evolution of heavy rainfall behaviour between Niño and Niña winters. However, the WP approach captures the variability of the probability of occurrences of synoptic situations generating heavy rainfall depending on ENSO and opening interesting perspectives for the analysis of heavy rainfall distribution in a non-stationary context.

\section{Introduction}

Traditionally, in the framework of the extreme value theory, the probability of extreme rainfall is estimated by fitting an extreme value distribution over a sample of rainfall observation series at a given location (Fréchet, 1927; Gumbel, 1958; Pickands, 1975; Coles et al., 2003). This approach assumes (strongly) that the sample used is independent, stationary and homogeneous. However, the heaviest rainfall events can have various atmospheric geneses (convective rainfall and frontal rainfall, for example) and they show generally strong seasonal variability (Djerboua and Lang, 2007). In a recent study, Allamano et al. (2011) showed the significant bias induced by neglecting the seasonality of hydrological extremes in determining extreme value probabilities. In this general framework, Garavaglia et al. $(2010,2011)$ proposed a multi-exponential weather pattern (MEWP) probability 
distribution for extreme rainfall based on a weather pattern (WP) and seasonal sub-sampling. Other authors recently used the WP concept to characterise extreme rainfall events (e.g. Ducić et al., 2012). More generally, since early WP classifications such as the subjective classification produced by Pague and Blandford (1897) over the northwestern US, the definition of WP classification at the synoptic scale has been shown to be useful for the estimation of statistical characteristics of hydroclimatic records such as precipitation or streamflow series at the local scale. Moreover, WP frequency of occurrence has been linked to global signals such as North Atlantic Oscillation (NAO) or El Niño-Southern Oscillations (ENSOs). For example, Fernández-González et al. (2011) investigated the dependence between NAO frequencies and Spanish WPs. Several studies showed the significant correlation between WP frequency and ENSO climate signals over northwestern America (Kimoto and Ghil, 1993; Chen and van den Dool, 1999; Robertson and Ghil, 1999; Sheridan, 2002; Stahl et al., 2006) or even over Louisiana (McCabe and Muller, 2002). Consequently, the link between global signals and hydroclimatic variables, which is investigated for instance by Fernández-González et al. (2011) and Schubert et al. (2008), can be explored through a WP classification approach. Casola and Wallace (2007) found significant correlations between ENSOs and the frequency of occurence of the four winter WPs they previously identified using a limited-contour clustering algorithm to the pentad (5-day average) $500 \mathrm{hPa}$ geopotential height field data for the PacificNorth American region. They also showed the existing link between frequency of occurence of extreme weather (coldest and wettest winter days) and the frequency of occurence of WPs, highlighting that this signal is much weaker for precipitation than for temperature extreme events. In conclusion and explaining the limits of the methodology used, they stated that "with the exception of the Pacific Northwest, the clustering method performs poorly in segregating incidences of extreme precipitation. We speculate that precipitation is inherently dependent on synoptic scale events that are associated with patterns smaller in spatial scale and shorter in time scale than the patterns captured here" (Casola and Wallace, 2007).

In this framework, the Coastal region of British Columbia (BC) represents a very interesting playground, since numerous authors have studied the links between the rainfall probability distribution over the Pacific Coast of North America and some large-scale climatological phenomena, such as ENSOs, the Pacific Decadal Oscillation (PDO) or the Pacific North America pattern (PNA). These oscillations are linked to both average winter rainy events (Yarnal and Diaz, 1986; Shabbar et al., 1997) and winter extreme events (Gershunov, 1998; Cayan et al., 1999) all over the North Pacific Coast. Concerning extreme rainfall, Higgins et al. (2000) pointed out the highest frequency of heavy rainfall events during the neutral years preceding warm ENSO winters. However, Kenyon and Hegerl (2010) did not find a clear, significant difference between El Niño winter extremes (defined as the largest amount of daily precipitation over a single day and over 5 days) and other winters over BC. In a recent study on the influences of climate mode variability on global extreme precipitation, Feldl and Roe (2011) showed that warm phases of ENSOs implied both changes of mean precipitation and precipitation distribution shapes over the American West. Zhang et al. (2010) also noted the clear influence of ENSOs and PDO on daily winter extreme precipitation values over North America, but with an unclear signal over BC, a region that is poorly studied due to a limited number of available data. Finally, Mass et al. (2011) mentioned natural variability as a possible explanation for the low increasing trend of extreme precipitation found over the Pacific Coast. Studying the genesis of Northern Washington floods, Neiman et al. (2011) showed that most floods are produced by "atmospheric river" (AR) situations, which are relatively narrow regions of the atmosphere that are responsible for most of the horizontal transport of water vapor outside of the tropics (the "Pineapple Express" is a well-known example of a strong AR that brings moisture from the Hawaiian tropics region to the North American west coast (Dettinger, 2004)). In AR situations over northwestern Washington, they showed that floods are observed on several watersheds depending on the orientation of the AR and the elevation distribution over the watershed areas. These results suggest some correlations between climate signals and rainfall behaviour over the Coastal region of BC. Even so, scientific questions on the nature of the correlations remain open. The WP classification appears thus to be a "medium-scale disaggregating tool" between climate signals and local rainfall observations and it deserves to be tested in this context of ENSO driving rainfall observations of the Northern Pacific coastal region.

The aim of this paper is thus to define a WP classification based on a bottom-up approach introduced by Garavaglia et al. (2010), which is useful for heavy rainfall analysis of the coastal $\mathrm{BC}$ region and to use the WP approach to study the links between ENSOs and BC heavy rainfall events. In coastal BC, the rainy season is mainly constituted by the winter months both for the common and the heaviest events. Heavy rainfall analysis has thus been limited in this study to a six winter months season, from October to March. More specifically, magnitude and frequency of heavy rainfall events will be quantified over different winter sets (all winter sets, Niño winter sub-sets and Niña winter sets). The method used for the WP classification and heavy rainfall analysis is summarised in Sect. 2. The data sets used in the study are described in Sect. 3, while Sect. 4 presents and discusses the results obtained. Finally, Sect. 5 draws conclusions.

\section{Methodology}

This section aims at presenting the methodology used in this study. The methodology used for the WP definition is 
presented in the Sect. 2.1, the multi-exponential weather pattern (MEWP) rainfall probabilistic model is described in the Sect. 2.2 and the methodology used for the quantification of ENSO influence on rainfall characteristics is presented in the Sect. 2.3.

\subsection{Definition of a weather pattern classification}

WPs are identified at the daily time step using a "bottom-up" approach: firstly, identifying rainfield patterns using rainfall information ("bottom" step); and secondly, projecting them into a geopotential height space for the final definition of WP ("up" step).

The goal of this weather pattern classification methodology is to group days having a similar atmospheric circulation pattern in a limited number of typical weather patterns. The weather pattern classification is thus defined at a regional scale and consists of the attribution of each observed day to one weather pattern. This regional weather pattern classification is then used at the local scale, for each daily rainfall series considered: the observed rainfall series is split into several rainfall sub-samples according to the weather pattern classification. This splitting is based on the hypothesis that rainfall events observed over a given area have different atmospheric geneses and thus a rainfall series sampling based on days having similar atmospheric circulation patterns produces more homogeneous rainfall sub-samples than considering the observed rainfall series as a unique series (Garavaglia et al., 2010). Geopotential height fields are used for the definition of WP classification since they clearly explain the variance of regional rainfall patterns (e.g. Littmann, 2000).

The main advantage of this methodology is that it produces a rainfall-oriented WP classification, but days without any rainfall observations are also classified: the approach only needs a limited calibration period (typically $20 \mathrm{yr}$ ) where both observed rainfall series and geopotential height fields are available over a given region in order to define several typical WP. The generated WP classification is finalized by using geopotential information. Then, it is possible to extend the classification beyond the calibration period by using only geopotential height fields. Since long geopotential height reanalyses exist, such as the National Oceanic and Atmospheric Administration (NOAA) 20th Century Reanalysis - a global 6 hourly geopotential height fields from 1871 to 2011 (Compo et al., 2011) - or as the EMULATE reanalyses - a daily mean sea level pressure reconstruction over Europe for the 1850-2003 period (Ansell et al., 2006) - the classification could be extended over significantly long periods. Boé and Terray (2008) applied a similar methodology combining both sea level pressure fields with daily precipitation fields for defining WPs over France and studying the link between WP frequency evolution and anthropogenic forcing for example. Applications of such approaches are particularly interesting for climate change impact studies, since only the geopotential height fields simulated by the General Circulation Models could be considered for predicting future WP frequencies for example.

The main limit of this methodology is that the WPs defined are only characterized by particular dynamical atmospheric situations (e.g. typical spatial distribution of low and high pressure systems over a given area) and not particular thermodynamic atmospheric situations (e.g. typical distribution of moisture amount over a given area). For example, considering dynamical and thermodynamical (such as moisture fluxes) description of atmospheric situations significantly improves the forecast performances (Obled et al., 2002), approach also included in statistico-dynamical downscaling methods (e.g. Beaulant et al., 2011) or statistical downscaling methods (e.g. Mezghani and Hingray, 2009).

The weather pattern classification methodology is fully described and used in Garavaglia et al. (2010) for the definition of eight French WPs and in Brigode et al. (2013) for the definition of five Austrian WPs. It is summarised in the following four steps.

\subsubsection{Selection of a rainy day population}

A sub-sample of the heaviest daily precipitations of the considered domain is selected using a spatial averaging criterion, whereby for each observed day, the average precipitation on the considered domain is calculated. All the observed days are ranked using this criterion. An arbitrary threshold (noted $T$ hereafter) typically within the 10 to $25 \%$ range (representing the balance between number of rainy days and precipitation magnitude of rainy day) is then used for defining rainy days sub-population. Thus, $T \%$ of observed days are considered as "rainy days", while $(100-T) \%$ of observed are considered as "non-rainy days" and are grouped in a non-rainy class.

\subsubsection{Hierarchical ascendant classification of the rainy day "shapes" fields}

The need for a classification more closely focused on "where it rains" than on "how much it rains" (i.e. having classes regrouping days that are particularly rainy in the same area rather than having classes regrouping days with the same amount of rain) is fulfilled by looking at the rainfall spatial distribution of each rainy day. For each rainy day, a rainfall shape field over the considered domain is estimated by normalising the daily amount of precipitation observed over each site of the considered domain by the daily average precipitation observed over the entire domain. A hierarchical ascendant classification (HAC) is then performed on the rainy day "shape" fields previously identified. The rainy classes are generated using the Ward method (1963), which iteratively chooses the grouping presenting the minimum intraclass inertia (Cheng and Wallace, 1993). The final number of rainfall classes is determined first by examining numerical 
criteria such as changes in intra-class inertia as a function of the number of classes and second by looking at the spatial distribution of each rainfall field class in the selected area. This choice is thus a mixture of objective numerical criteria analysis and subjective climatological assessment.

\subsubsection{Projection of the rainy classes into one geopotential height field space}

The daily synoptic situation over the area of interest is described using gridded geopotential height fields at two pressure levels (700 and $1000 \mathrm{hPa}$ ), twice a day (at 0 and $24 \mathrm{~h}$, allowing a dynamical description of the geopotential height fields over $24 \mathrm{~h}$ ). Thus, each day $(d)$ is characterised by two couples of geopotential height fields: the first couple is composed of a $700 \mathrm{hPa}$ geopotential field at $0 \mathrm{~h}$ and a $700 \mathrm{hPa}$ geopotential at $24 \mathrm{~h}$ (equivalent to the $700 \mathrm{hPa}$ geopotential field of the day $(d+1)$ at $0 \mathrm{~h})$ and the second couple is composed of a $1000 \mathrm{hPa}$ geopotential field at $0 \mathrm{~h}$ and a 1000 $\mathrm{hPa}$ geopotential field at $24 \mathrm{~h}$ (equivalent to the $1000 \mathrm{hPa}$ geopotential field of the day $(d+1)$ at $0 \mathrm{~h})$. These options are the results of previous studies on quantitative precipitation forecasting using the analogue method in France (Guilbaud and Obled, 1998; Obled et al., 2002; Bontron, 2004). The $1000 \mathrm{hPa}$ fields are strongly correlated to the rainfall ones since they describe the pressure situation near the surface and catch the local patterns, while the $700 \mathrm{hPa}$ fields give information at a larger scale and catch the synoptic systems and movements. The geopotential space used for the French WP classification (Garavaglia et al., 2010) and the Austrian WP classification (Brigode et al., 2013) was composed of these four geopotential fields defined, respectively, on 110 grid points centred on southeastern France and on 54 grid points centred on the Western Alps. Defining the geopotential height space that gives robust information for explaining the rainfall-generating processes coming from the synoptic scale is the critical point of these "up" steps. Once one geopotential space is defined, the centroids of the rainy classes and of the non-rainy class previously identified are calculated in this space, by estimating the four average geopotential fields of the days composing each rainy class. Note that at this stage of the methodology, the non-rainy class is constituted by $(100-T) \%$ of all the observed days (the less rainy days in average over the studied domain) while the rainy classes are composed by $T \%$ of all the observed days (the most rainy days in average over the studied domain). Finally, each class centroid is characterised by two couples of geopotential height fields $(700 \mathrm{hPa}$ at $0 \mathrm{~h}, 1000 \mathrm{hPa}$ at $0 \mathrm{~h}, 700$ at $24 \mathrm{~h}$ and $1000 \mathrm{hPa}$ at $24 \mathrm{~h})$.

\subsubsection{Re-assignment of each day to a weather pattern}

The last classification step consists in the re-assignment of each day (considered as rainy or non-rainy) to a given WP in estimating Teweles and Wobus (1954) distances between the day considered and all the class centroids. The need to focus on the field shapes is the main criterion for choosing this distance, which considers the synoptic circulation gradients (Obled et al., 2002). The final Teweles-Wobus distance between one particular day and one class centroid is defined as the sum of the four Teweles-Wobus distances between the four geopotential height fields $(700$ and $1000 \mathrm{hPa}$ at $0 \mathrm{~h}$ and 700 and $1000 \mathrm{hPa}$ at $24 \mathrm{~h}$ ) of the considered day and of the considered centroid. The major changes between the rainy days classification (hierarchical ascendant classification step) and the final weather pattern classification are mainly due to the distribution of previous "non-rainy days" to rainy weather patterns. The arbitrary threshold $T$ used for defining rainy days has no influence on this final step since all observed days are classified in terms of distance between average geopotential situations of the identified WPs and geopotential situations of each day, grouping days having similar synoptic situations and not considering their observed rainfall fields.

\subsection{The multi-exponential weather pattern (MEWP) rainfall probabilistic model}

The multi-exponential weather pattern (MEWP) probabilistic model (Garavaglia et al., 2010, 2011) has been applied on each rainfall series considered over the studied domain, in order to compute a cumulative distribution function of daily rainfall amount for each series up to extreme return period. This rainfall probabilistic model is based on a seasonal and weather pattern sub-sampling of rainfall series and thus used a regional weather pattern classification previously defined. For each season and each weather pattern, an exponential law is fitted on the heaviest rainfall observations of the considered daily rainfall sub-sample (defined with a threshold value, typically the quantile 0.70 ). Note that MEWP distributions are fitted on a sample of "centred rainy events", noted $\mathrm{CR}$ hereafter. The CR population is defined, for each rainfall series, as days having higher precipitation values than the previous and following days. Using this sub-sampling allows working on a distribution of (so-considered) independent events, which is much denser than annual maximums for example.

For a given rainfall series, the MEWP distribution is thus characterized by three parameters for each season and each WP:

- the frequency of the CR observation sub-sample (noted $p$ hereafter, expressed in percentage), estimated as the ratio between the number of $\mathrm{CR}$ observations of each WP and the total number of CR observations within the considered season;

- the threshold quantile (noted $u$ hereafter, expressed in $\mathrm{mm} 24 \mathrm{~h}^{-1}$ ), estimated as a quantile of the CR observation sub-sample (typically the quantile 0.70 ); 
- the scale parameter (noted $\lambda$ hereafter, expressed in $\mathrm{mm} 24 \mathrm{~h}^{-1}$ ), estimated as the difference between the mean value of the $\mathrm{CR}$ observations which are higher than the previously defined threshold quantile value (the parameter $u$ ) and the previously defined threshold quantile value (the parameter $u$ ). It is equivalent to the scale parameter of an exponential law fitted on the CR observations greater the threshold quantile values.

Formulation of seasonal MEWP distribution is reported in the Eq. (1), where $i$ is the season studied, CR are the central rainfall event observations, $j$ is the WP studied, $n_{\mathrm{WP}}$ is the number of WPs, $p$ is the CR event probability of occurrence of the WP, $F$ is the marginal distribution, $u$ is the threshold for heavy rainfall observation selection and $\lambda$ is the parameter of the exponential law. Note that hereafter, parameter $u$ is estimated for each season and WP as the $0.80 \mathrm{CR}$ quantile.

$$
\begin{aligned}
F^{i}(\mathrm{CR}) & =\sum_{j=1}^{n_{\mathrm{WP}}} F_{j}^{i}(\mathrm{CR}) * p_{j}^{i} \\
F^{i}(\mathrm{CR}) & =\sum_{j=1}^{n_{\mathrm{WP}}}\left[l-\exp \left(-\frac{\mathrm{CR}-u_{j}^{i}}{\lambda_{j}^{i}}\right)\right] * p_{j}^{i}
\end{aligned}
$$

The Eq. (2) gives the relation between MEWP probability and return period, in years, where $n$ is the size of the rainfall observation sample considered (for example, the number of winter CR events of the weather pattern one) and $N$ is the number of years of the $\mathrm{CR}$ series considered.

$$
T(\mathrm{CR})=\frac{1}{1-F(\mathrm{CR})^{\frac{n}{N}}}
$$

\subsection{Quantification of ENSO influences on rainfall characteristics}

\subsubsection{Influence of ENSO on WP frequency and on MEWP parameters and distributions}

Each observed winter (ONDJFM) will firstly be characterised as "Niño winter" or "Niña winter", according to SST Niño 3.4 Index (Trenberth, 1997), described in Sect. 3.2.2. Three winter sub-sets will thus be defined (All winters, Niño winters and Niña winters). The frequency of each WP is then estimated on the three winter sets and compared for each WP. Then, more local tests will be performed to determine the influence of ENSO on rainfall characteristics over several coastal BC rainfall stations. A MEWP distribution will be defined for each rainfall series considered and for each of the three winter sets (All winters, Niño winters and Niña winters). The MEWP distribution parameters are then compared for each rainfall station. Finally, the three MEWP heavy rainfall estimations are compared for each station and each winter set considered, by looking at $1000 \mathrm{yr}$ return period precipitation values.

\subsubsection{Bootstrap simulations for testing the difference significance}

The significance of WP frequency, MEWP parameters and MEWP heavy rainfall estimation differences between the three different winter sets has been evaluated by performing nonparametric bootstrap simulations, initially proposed by Efron (1979) and classically used in statistical characterization of uncertainty and sensitivity analysis. The idea is thus to evaluate ENSO influences on WP frequency, MEWP parameters and MEWP heavy rainfall estimations regarding to natural variability which is quantified by sub-sampling observed winters without consideration of their ENSO characteristics.

For testing the significance of the WP frequency difference between the three different winter sets, 1000 random winter combinations are generated among all the winters available over the period considered. Each of the 1000 random winter combinations is composed by the same number of winters, which is equal to half of the total number of winters of the period considered, i.e. for a given period composed of 20 winters, 1000 combinations of 10 winters will be generated. Note that the bootstrap simulation performed does not allow having a particular winter more than once in one combination of winters. WP frequency will be finally estimated on each of the 1000 combinations generated, in order to quantify the natural variability of WP frequency and thus to compare the frequency estimated on particular ENSO winter sub-sets compared to all the sub-sets (without consideration for ENSOs) generated by bootstrap simulations. Note that a similar methodology has been applied by Casola and Wallace (2007) for identifying the correlation between ENSO and the frequency of occurrence of four Pacific-North American winter WPs.

The same methodology is applied for each rainfall series considered in order to quantify the significance of MEWP parameter differences and MEWP heavy rainfall estimation differences. MEWP parameters will be defined for each station on 1000 random winter combinations, in order to quantify the impact of the natural variability (without consideration for ENSOs) on the MEWP parameters and distributions and thus to compare the parameters estimated on particular ENSO subsets with all the subsets generated by bootstrap simulations.

\section{Data}

This section aims at presenting the two data sets used in this study. The first data set, used for the coastal BC WP definition and described in the Sect. 3.1, consists of 177 daily rainfall series available over the 1983-2003 period and 338 daily geopotential height grid points available over the 1871-2008 period. The second data set, used for the quantification of ENSO influence on rainfall characteristics and described in the Sect. 3.2, consists of 45 daily rainfall series available over 
(a)

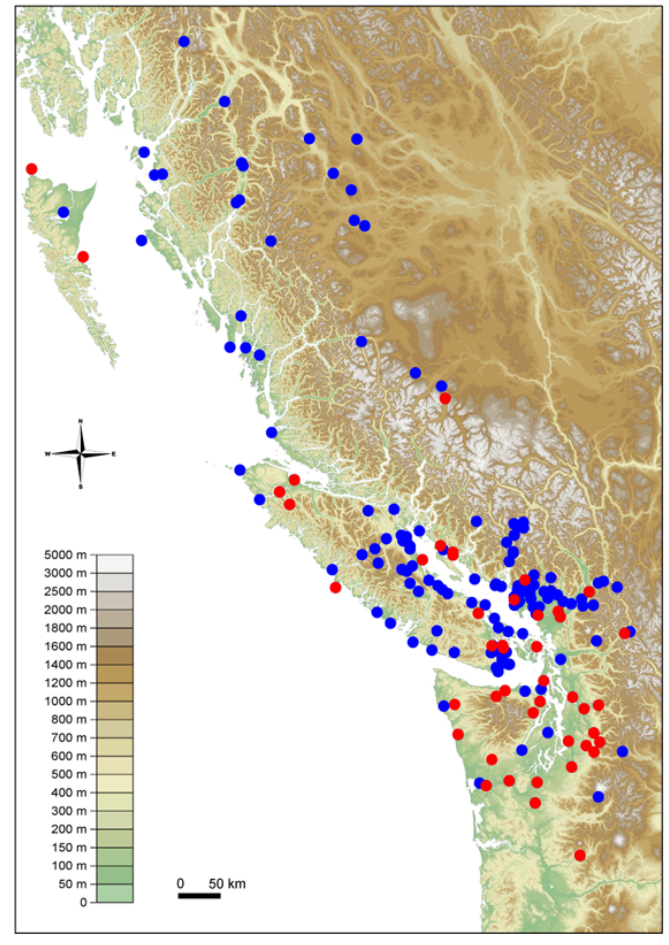

(b)

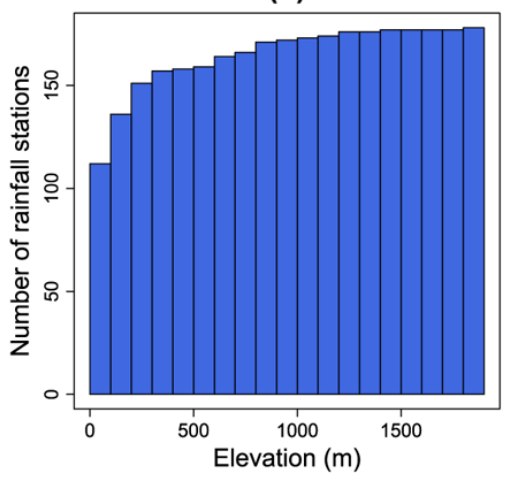

(c)

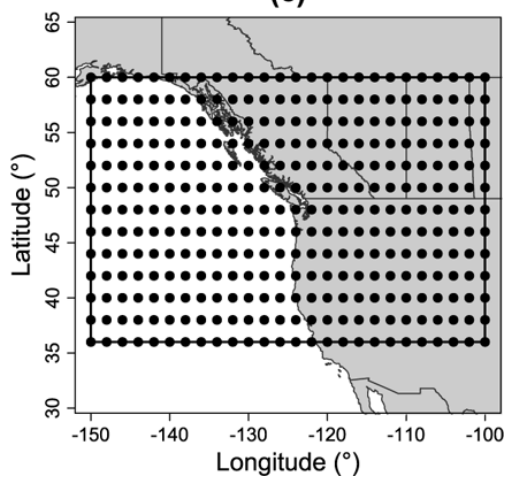

Fig. 1. (a) Location of the 177 rainfall series used for the coastal BC WP definition (blue and red dots) and of the 45 rainfall series used for the quantification of the influence of ENSO on rainfall characteristics (red dots). Elevation data has been extracted from the SRTM $90 \mathrm{~m}$ data set (Jarvis et al., 2008). (b) Elevation distribution of the 177 coastal BC rainfall series used for the coastal BC WP definition. (c) Location of the 338 geopotential height grid points used for the coastal BC WP definition.

the 1951-2001 period and an index describing the ENSO characteristics of each observed winter over the 1871-2008 period.

\subsection{Data sets used for WP definition}

WPs have been defined combining both rainfall information, captured by daily precipitation series, and synoptic information, captured by daily geopotential height reanalysis.

\subsubsection{Rainfall series}

A total of 177 stations were selected for the definition of coastal BC rainfall classes in order to have a good representation of local climatology and local rainy patterns. Daily precipitation data is available on each of the 177 stations for the 1983-2003 period, allowing the definition of rainfall classes for this $21 \mathrm{yr}$ period. Note that the stations used are located in the coastal BC region (Canada) and also in the Western part of the Washington State (USA). Hereafter, this region will be called coastal BC. The data quality has been checked, looking for statistically abnormal trends for each series compared to the nearest ones and looking for aberrant data. Location of the rainfall stations is reported in Fig. 1a with blue and red dots, and elevation distribution of these stations is plotted in Fig. 1b.

\subsubsection{Geopotential height fields}

The geopotential height fields, provided by the Twentieth Century Reanalysis Project data set (Compo et al., 2011) from the National Oceanic and Atmospheric Administration (NOAA) are defined on a $2^{\circ}$ grid spacing from 1871 to 2008 for both 700 and $1000 \mathrm{hPa}$. The geopotential space was chosen and is defined on 338 points centered on the Washington State coast, from $-150^{\circ} \mathrm{W}$ to $-100^{\circ} \mathrm{W}$ and from $36^{\circ} \mathrm{N}$ to $60^{\circ} \mathrm{N}$. This assessment was made looking at several historical storm synoptic situations: the geopotential space size and position has to be defined in order to catch these storm systems, which mainly come from the Pacific Ocean, but also from inland systems. Since no optimization procedure has been applied in order to select the final geopotential space size and position, it could be an interesting perspective for further research, by applying the methodology introduced by Brigode et al. (2013) for example. Spatial coverage of the 338 point grid is shown on Fig. 1c with black dots. Note that using both 500 and $1000 \mathrm{hPa}$ (instead of using 700 and 1000 $\mathrm{hPa}$ ) fields was also tested, showing no major differences 


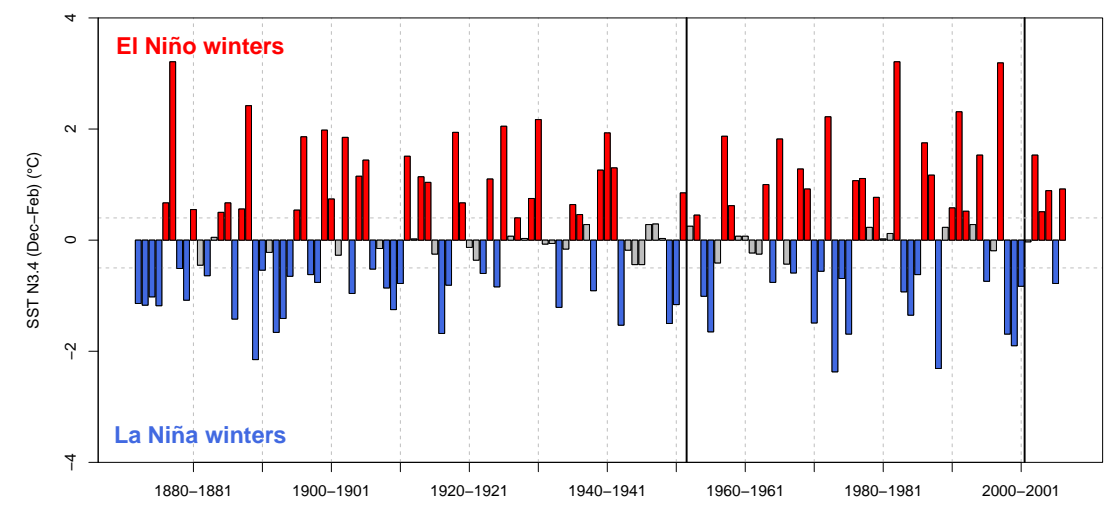

Fig. 2. Classification of 1872-2007 winters (ONDJFM) using SST Niño 3.4 Index (Trenberth, 1997), resulting in La Niña winters (blue colour), neutral winters (grey colour) and El Niño winters (red colour). The 1951-2001 period (the period used for quantification of the influence of ENSO on rainfall characteristics) is highlighted by black vertical lines.

in terms of the patterns identified. Thus, the geopotential space further used is made up of four fields of 338 points for each day: 700 and $1000 \mathrm{hPa}$ at $0 \mathrm{~h}$ and 700 and $1000 \mathrm{hPa}$ at $24 \mathrm{~h}$. The geopotential height data set was first extracted over the 1983-2003 period, which is the time period covered by the rainfall data set. In the second step, the entire available geopotential height data set (1871-2008) was used, extending the WP classification defined on the 1983-2003 period over a longer period.

\subsection{Data sets used for the quantification of ENSO influence on rainfall characteristics}

\subsubsection{Rainfall series}

Long precipitation records are needed when impacts of climate signals such as ENSO on rainfall are studied. 45 series with $51 \mathrm{yr}$ of data (from 1951 to 2001) were selected. The position of the stations is shown in Fig. 1a with red dots. Note that these stations are mainly in low-elevation areas and are included in the rainfall data sets used for the definition of weather patterns. The influence of ENSO on rainfall characteristics will thus be assessed over this $51 \mathrm{yr}$ period, starting in 1951 and finishing in 2001.

\subsubsection{ENSO classification}

El Niño-Southern Oscillations are further described with the SST Niño 3.4 Index, which consists in monthly sea surface temperature (SST) anomalies in degrees Celsius estimated on the 3.4 Niño region, bound by $120^{\circ} \mathrm{W}-170^{\circ} \mathrm{W}$ and $5^{\circ} \mathrm{S}-$ $5^{\circ} \mathrm{N}$ (Trenberth, 1997). A classification of ENSO winters has been defined using this data set: each winter (ONDJFM) is characterised by an average monthly SST anomaly estimated on the December, January and February months. Winters with SST anomalies below $-0.5^{\circ} \mathrm{C}$ are considered as La Niña winters, winters with SST anomalies above $-0.5^{\circ} \mathrm{C}$ and below $0.4^{\circ} \mathrm{C}$ are considered as neutral winters and win- ters with SST anomalies above $0.4{ }^{\circ} \mathrm{C}$ are considered as El Niño winters. The ENSO winter classification is illustrated on Fig. 2, showing that 53 Niño winters and 48 Niña winters are identified over the 1872-2007 period (the first period used for the quantification of the influence of ENSO on WP frequency) and that 20 Niño winters and 17 Niña winters are identified on the 1951-2001 period (the second period used for the quantification of the influence of ENSO on WP frequency and the period used for quantification of the influence of ENSO on rainfall characteristics).

\section{Results}

\subsection{Empirical evidence of the relation between ENSOs and coastal $\mathrm{BC}$ rainfall distribution}

Empirical evidence on the correlation between coastal BC rainfall distribution and ENSO are investigated first.

Figure 3 presents the relative differences between rainfall characteristics of all the record periods (51 winters) and over the Niña winters (17 winters) and the relative differences between rainfall characteristics of all record periods (51 winters) and over the Niño winters (20 winters) estimated for each of the 45 rainfall stations. Four characteristics were estimated: (a) the average of winter precipitation values, (b) the frequency of the days when more than $20 \mathrm{~mm}$ were observed, (c) the 0.70 percentile and (d) the 0.95 percentile of the rainfall distributions. The blue and red histogramms represent for each of the four graphs the distributions of the $\mathrm{x}$ and the $\mathrm{y}$ axis values. Each point represents one of the 45 rainfall series. For the majority of the 45 coastal $\mathrm{BC}$ rainfall series considered, the average winter amount of rain is higher during Niña winter compared to all winters since numerous points are in the right part of the Fig. 3a and average winter amount of rain is lower during Niño winter compared to all winters since numerous points are in the bottom part of the Fig. 3a. Thus, significant differences are observed in terms of average 

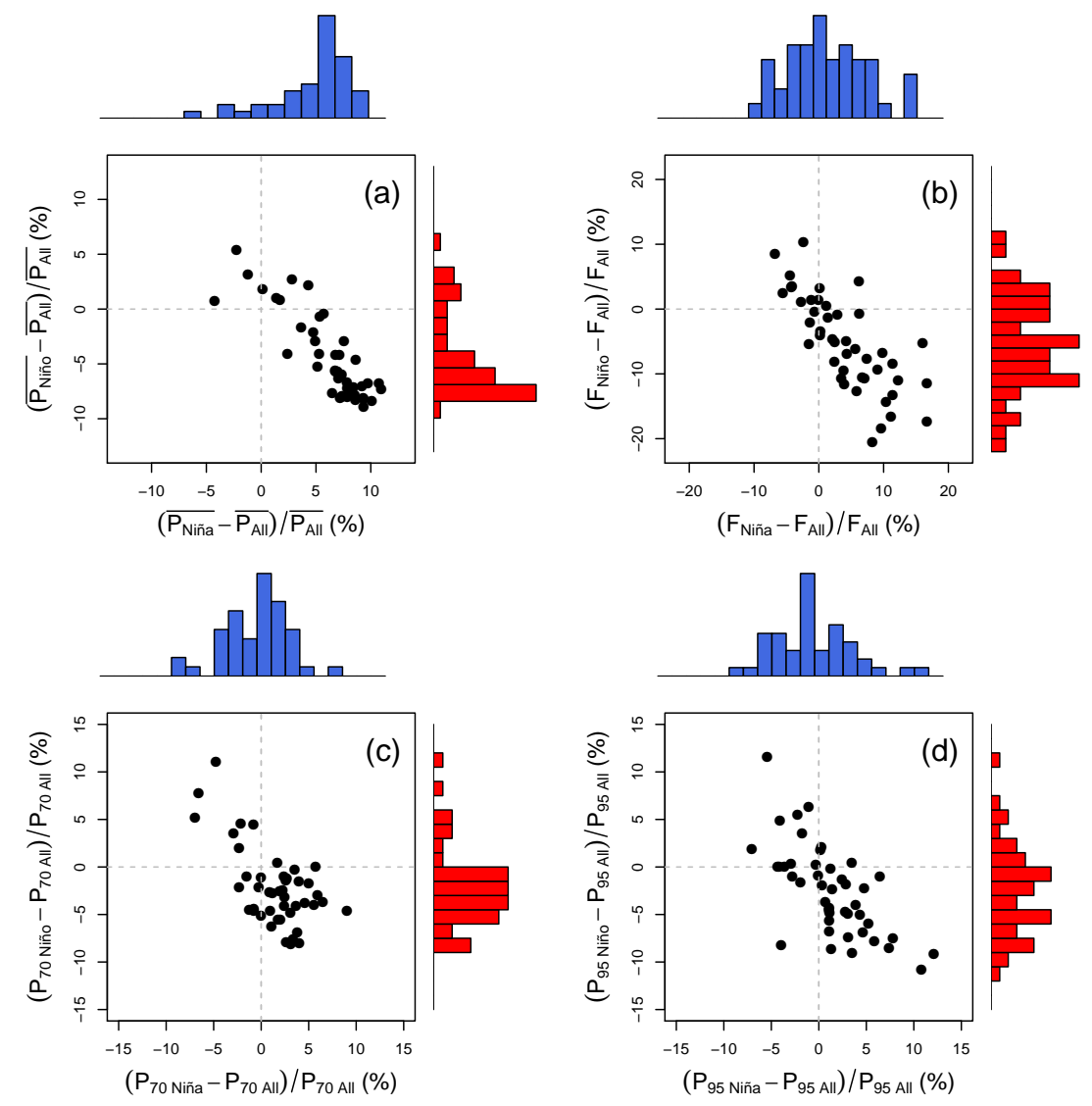

Fig. 3. Relative difference between rainfall characteristics of the whole record period (51 winters) and over the Niña winters (17 winters) and relative difference between rainfall characteristics of the whole record period (51 winters) and over the Niño winters (20 winters) for each station considered and for four rainfall characteristics: (a) the average of winter precipitation values, (b) the frequency of the days when more than $20 \mathrm{~mm}$ were observed, (c) the 0.70 percentile and (d) the 0.95 percentile of the rainfall distributions. Blue (Niña winters) and red (Niño winters) histograms represent for each of the four graphs the distributions of the (x) and the (y) axis values.

winter amount of rain over coastal $\mathrm{BC}$, with about $8 \%$ increase in rain during Niña winters compared to all winters on average over the 45 stations considered, and $8 \%$ decrease in rain during Niño winters compared to all winters on average over the 45 stations considered. The difference between Niño and Niña winters is less significant in terms of frequency of heavy rainy days (here days with $20 \mathrm{~mm}$ or more observed). Nevertheless, a majority of points are in the bottom part of the Fig. 3b, highlighting a lower frequency of heavy rainfall events during Niño winters compared to all the winters for the 45 considered stations. Finally, heavy (percentile 0.70) and extreme empirical quantiles (percentile 0.95) also show an unclear signal, with percentile values slightly lower during Niño winters compared to all winters and slightly higher during Niña winters compared to all winters, especially for the heavy rainfall event percentile.

\subsection{Coastal BC WP definition for heavy rainfall analysis}

This subsection aims at presenting the five coastal BC WPs defined. The top $20 \%$ days are selected as "rainy days" in this study for identifying rainfall classes and correspond here to days where the spatial rainfall average over the considered 177 rainfall stations is greater than $8 \mathrm{~mm}$. For a $20 \mathrm{yr}$ record period, this $20 \%$ threshold selects 1524 rainy days. The other 6136 days are, at this classification stage, grouped in the nonrainy class.

Figure 4 presents (a) the dendogram, (b) the evolution of the intra-class inertia and of (c) the 1-order intra-class inertia differences with the number of rainfall classes. Each difference "Dn" (plotted in Fig. 4c) has been estimated as the absolute value of the difference between the intra-class inertia estimated for $(n+1)$ rainfall classes and the inertia estimated for $(n)$ classes. Note that good classifications are characterized by high intra-class inertia values, and that a peak of intra-class inertia value for $(k)$ classes followed by a significant loss of intra-class inertia value for $(k+1)$ classes means a good classification of $(k+1)$ classes. The change in intra-class inertia clearly suggests the choice of four rainfall classes (highlighted with four red boxes in the dendogram presented in Fig. 4a) moving from three to four rainfall 
Table 1. Teweles-Wobus distances estimated between the 16 October 2003 synoptic situation and the five class centroids estimated for the 1000 and $700 \mathrm{hPa}$ geopotential height fields at $0 \mathrm{~h}$ and for the 1000 and $700 \mathrm{hPa}$ geopotential height fields at $24 \mathrm{~h}$. In this case, the 16 October 2003 is finally attributed to the third weather pattern. Note that Teweles-Wobus distances are unitless.

\begin{tabular}{lccccc}
\hline & RC1 & RC2 & RC3 & RC4 & RC5 \\
\hline $1000 \mathrm{hPa}$ at $0 \mathrm{~h}$ & 57 & 52 & 56 & 66 & 76 \\
$1000 \mathrm{hPa}$ at $24 \mathrm{~h}$ & 52 & 53 & 48 & 58 & 78 \\
$700 \mathrm{hPa}$ at $0 \mathrm{~h}$ & 74 & 75 & 70 & 79 & 92 \\
$700 \mathrm{hPa}$ at $24 \mathrm{~h}$ & 65 & 68 & 59 & 70 & 94 \\
\hline Distance sums & 248 & 248 & 233 & 273 & 340 \\
\hline
\end{tabular}

classes leads to a limited intra-class inertia decrease, while moving from four to five rainfall classes leads to a large intraclass inertia decrease. Finally, the rainy days classification is composed by four rainfall classes and of one supplementary non-rainy class constituted at this stage of the $80 \%$ less rainy days (with spatial average below $8.1 \mathrm{~mm}$ in this case).

Table 1 illustrates the final WP classification method step (Re-assignement of each day to a WP) and shows the 20 Teweles-Wobus distances estimated between the five rainfall class centroids (Rainfall Class (RC) 1 to 5) and the 16 October 2003 synoptic situation over coastal BC for the $1000 \mathrm{hPa}$ geopotential height fields at $0 \mathrm{~h}$, the $1000 \mathrm{hPa}$ geopotential height fields at $24 \mathrm{~h}$, the $700 \mathrm{hPa}$ geopotential height fields at $0 \mathrm{~h}$ and the $700 \mathrm{hPa}$ geopotential height fields at $24 \mathrm{~h}$. Note that the 16 October 2003 day was classified as a member of the non-rainy class (in $80 \%$ of all the observed days considered as non-rainy days) at the end of the hierarchical ascendant classification step. The sum of the four Teweles-Wobus distances is minimal for the third weather pattern (233); the 16 October 2003 is thus attributed to the third weather pattern. This example highlights the major changes between the rainy days classification (hierarchical ascendant classification step) and the final weather pattern classification which are mainly due to the distribution of previous "non-rainy days" to rainy weather patterns.

Figure 5 shows, for each of the five coastal BC WPs, (a) the $1000 \mathrm{hPa}$ geopotential height anomaly fields, (b) the station mean precipitation amount, (c) the station ratio between the mean precipitation amount and the general precipitation amount (considering all WPs) and (d) the monthly frequency estimated over the 1983-2003 period. WP1 groups rainy days throughout the coastal $\mathrm{BC}$ region. WP2 is characterised by a northwestern-southeastern circulation which engendered particularly rainy events in the Washington State stations and Vancouver City area. WP3 groups days with south-west-east-north circulations, which bring a lot of rain in the central part of the Vancouver Island region. WP4 days are characterised by weaker south-west-north-east circulation which engendered rainy days in the northern part of the coastal BC region. Finally, the non-rainy pattern WP5 comprises typical anticyclonic situations, with essentially nonrainy days over coastal $\mathrm{BC}$ region.

Table 2 summarises yearly and seasonal frequencies of the five coastal BC WPs for the 1871-2008, 1951-2001 and 1983-2003 periods. The WP frequencies exhibit a clear seasonal signal, with rainy patterns (WP1 to WP4) occurring mainly in the winter months, while summer months are characterised mostly by the anticyclonic pattern WP5 (more than $50 \%$ of summer days are assigned to anticyclonic weather pattern). Note that WP1 exhibits a constant seasonal frequency throughout the year compared to the other ones. WP1 is not clearly defined in terms of geopotential height anomaly and rainfall pattern (showed in Fig. 5) and could thus be considered as a mix of different rainy days over the entire coastal $\mathrm{BC}$ region which is consequently not characterized by a clear seasonal frequency signal. WP frequencies seem to be relatively stationary over time since frequencies over the 19832003 period ( $21 \mathrm{yr}$ period used for the definition of the WP centroids) are equivalent to frequencies over the 1871-2008 period.

\subsection{MEWP parameters and distributions}

In this section, a spatial analysis of the scale parameter values ( $\lambda$ parameter of Eq. 1) obtained over 45 rainfall stations and an example of a MEWP distribution are illustrated.

Figure 6a shows ratios estimated for each rainfall station and each WP between the scale parameter value of the WP considered and the average value of the five scale parameter values for the station considered. One particular station (McMillin reservoir, Washington State) is highlighted on this map since it will be used as an example of the construction of a MEWP distribution. Thus, Fig. 6b shows for each WP the CR sub-samples of the WP considered and the exponential distribution fitted. Finally, Fig. $6 \mathrm{c}$ presents the final MEWP distribution of the McMillin reservoir rainfall series, which is a combination of the five WP exponential distributions weighted by the CR occurrence of each WP, using Eq. (1). Return periods are obtained using Eq. (2).

The comparison of the relative scale parameter values plotted in Fig. 6a reveals that several coastal BC regions have WPs which are particularly intense in terms of heavy precipitation events related to the other WPs. Thus, WP2 scale parameter values are clearly the most important scale parameter values for the Washington State stations, coherently with the rainfall spatial distribution of the WP2 days (shown in Fig. 5c), which are particularly rainy in this southern coastal area. Similarly, stations with particularly high WP3 and WP4 scale parameter values compared to the other scale parameter values are located in the Vancouver City area and on the west coast of Vancouver Island. Finally, scale parameter values of WP1 are close to the average value of the five scale parameter values for each station, highlighting a WP with the same relative importance over the whole domain and WP5 scale 

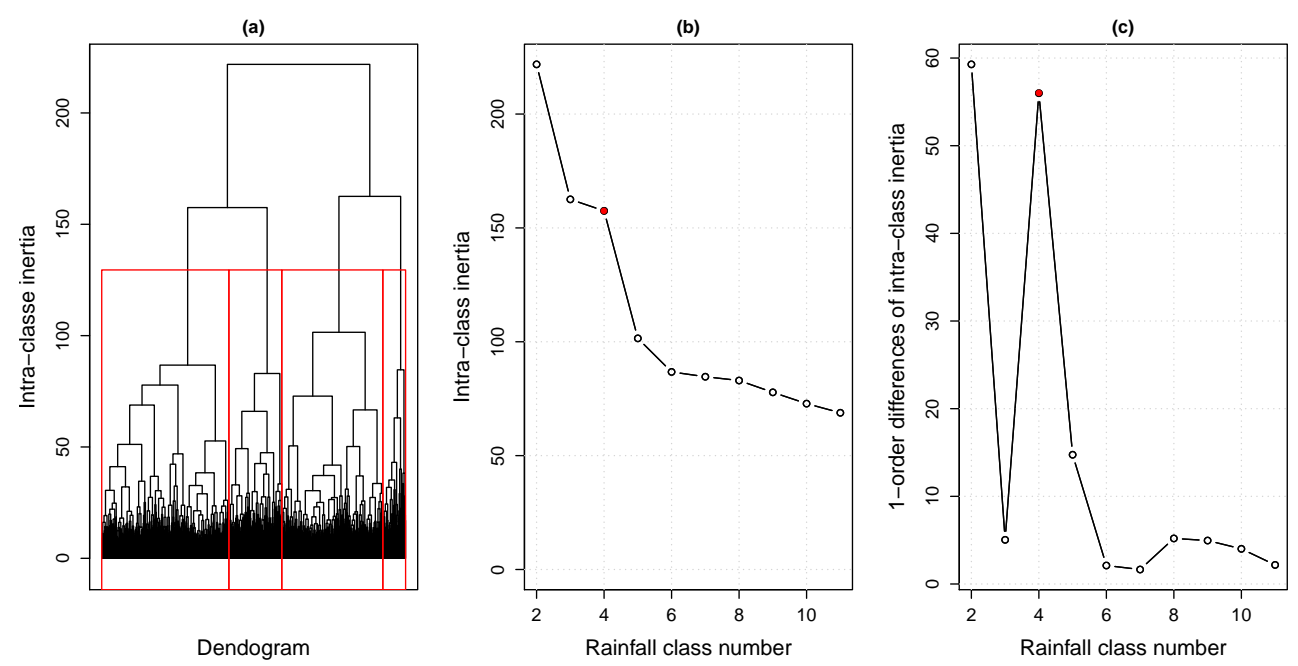

Fig. 4. (a) Dendogram obtained from Hierarchical Ascendant Classification of coastal BC 1524 rainy days. (b) Intra-class inertia and (c) 1order intra-class inertia differences evolution with the number of classes. Red boxes highlight the four rainfall classes identified and red points highlight their intra-class inertia.

Table 2. Yearly and seasonal frequencies of the five coastal BC WP for 1871-2008, 1951-2001 and 1983-2003 periods.

\begin{tabular}{|c|c|c|c|c|c|c|c|c|c|}
\hline & \multicolumn{3}{|c|}{ 1871-2008 } & \multicolumn{3}{|c|}{ 1951-2001 } & \multicolumn{3}{|c|}{ 1983-2003 } \\
\hline & Year & ONDJFM & AMJJAS & Year & ONDJFM & AMJJAS & Year & ONDJFM & AMJJAS \\
\hline WP1 & $11 \%$ & $11 \%$ & $10 \%$ & $10 \%$ & $9 \%$ & $10 \%$ & $9 \%$ & $7 \%$ & $10 \%$ \\
\hline WP2 & $14 \%$ & $23 \%$ & $5 \%$ & $15 \%$ & $24 \%$ & $6 \%$ & $15 \%$ & $23 \%$ & $7 \%$ \\
\hline WP3 & $15 \%$ & $20 \%$ & $10 \%$ & $16 \%$ & $19 \%$ & $12 \%$ & $17 \%$ & $21 \%$ & $13 \%$ \\
\hline WP4 & $25 \%$ & $33 \%$ & $17 \%$ & $28 \%$ & $36 \%$ & $19 \%$ & $27 \%$ & $36 \%$ & $19 \%$ \\
\hline WP5 & $35 \%$ & $12 \%$ & $58 \%$ & $32 \%$ & $12 \%$ & $53 \%$ & $32 \%$ & $12 \%$ & $51 \%$ \\
\hline
\end{tabular}

parameter values are regionally the lowest scale parameter values since these days are mainly days without any observed rain. It is thus interesting to note that Fig. $6 \mathrm{a}$ is similar to Fig. 5c in terms of spatial distribution of each WP relative importance: each WP is similarly important in terms of average amount of precipitation and in terms of scale parameter values compared to the other WPs. This figure highlights that the coastal BC WP classification is useful for splitting observed precipitation series into more homogeneous subsamples (i.e. sub-samples constituted by days having similar atmospheric circulation patterns) and thus identifying for each station the synoptic situations that generate the highest hazard in terms of heavy rainfall events. Thus, in this area of coastal BC, the highest heavy rainfall hazard is mainly generated by WP2 for the major part of the northwestern Washington region and Vancouver City region, by WP3 for the Vancouver Island region and by WP4 for the northern coastal BC region.

Finally, an example of a MEWP probability distribution is shown with the McMillin reservoir rainfall series. This station is located in northwestern Washington State at $157 \mathrm{~m}$ above mean sea level. The WP sub-sampling illustrated in
Fig. 6b reveals five sub-populations characterised by different heavy rainfall records. WP2 thus clearly contains the heaviest rainy days of this rainfall series. Note that the final MEWP distribution illustrated in Fig. 6c fits relatively well with the heaviest observations and that the tail of the distribution is equivalent to the tail of the WP2 exponential distribution. Thus, the heaviest rainfall events observed for the McMillin reservoir station occurred under WP2, leading thus to high scale parameter for WP2 related to other WPs for that station and finally leading to a general rainfall distribution tail driven by WP2 rainfall distribution tail.

\subsection{Link between ENSOs and coastal BC WP frequencies}

In this section, the link between El Niño-Southern Oscillation anomaly and the frequency of each coastal BC WP is analysed.

Figure 7 presents winter frequencies of the five coastal BC WPs estimated on different year sets. The left graph summarises empirical winter frequency observed on the 53 Niño winters and 48 Niña winters over the 1871-2008 period (red and blue dots, respectively) while right graph summarises the 
(a)
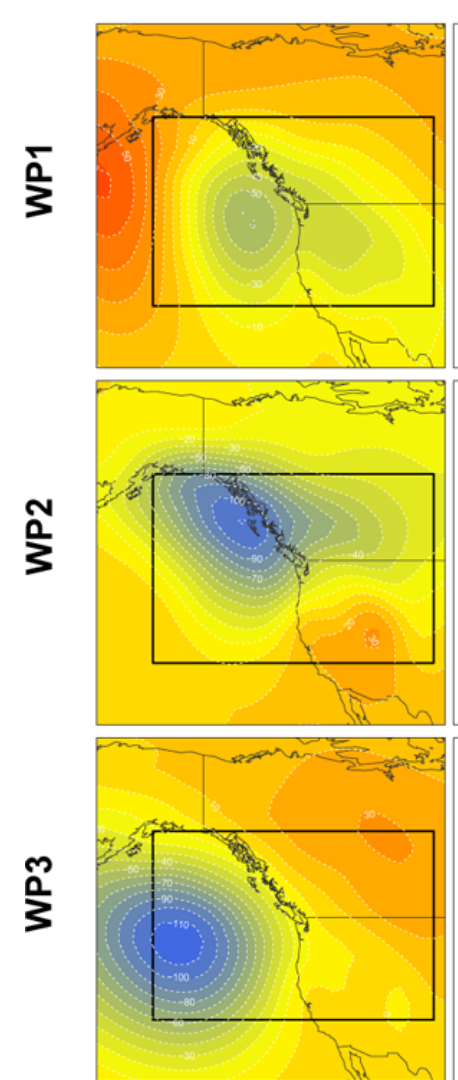

ڤั

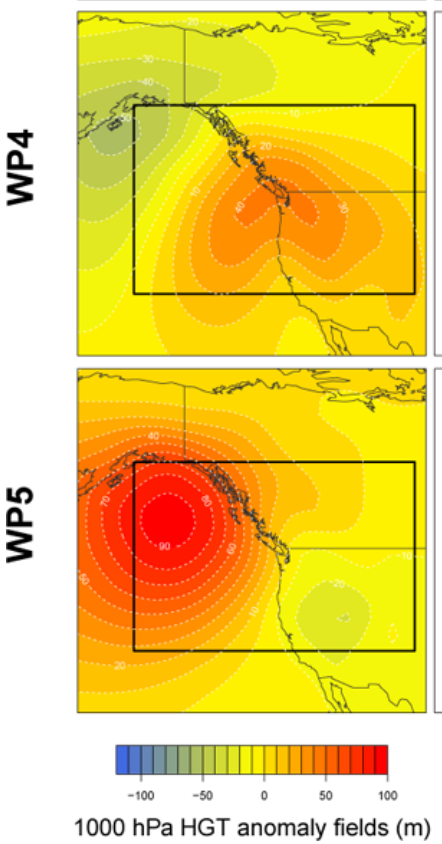

(b)
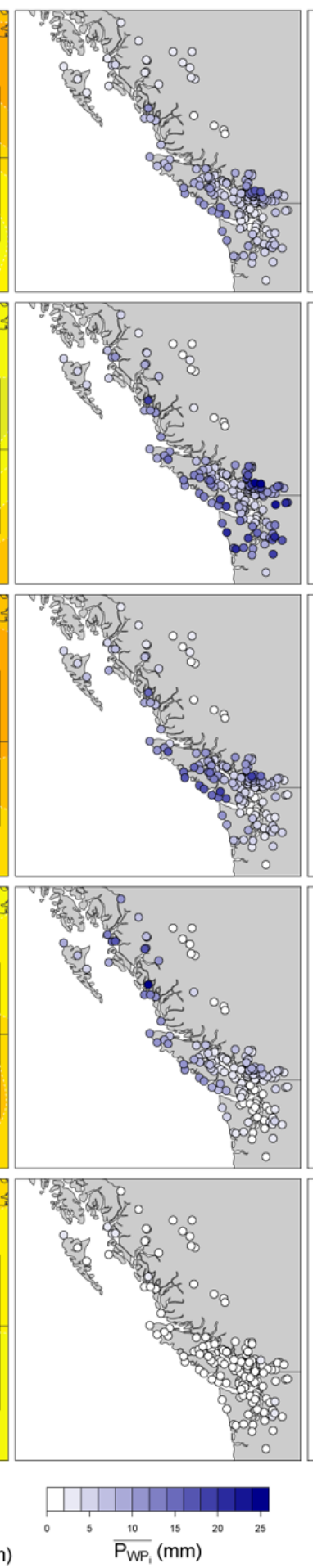

(c)
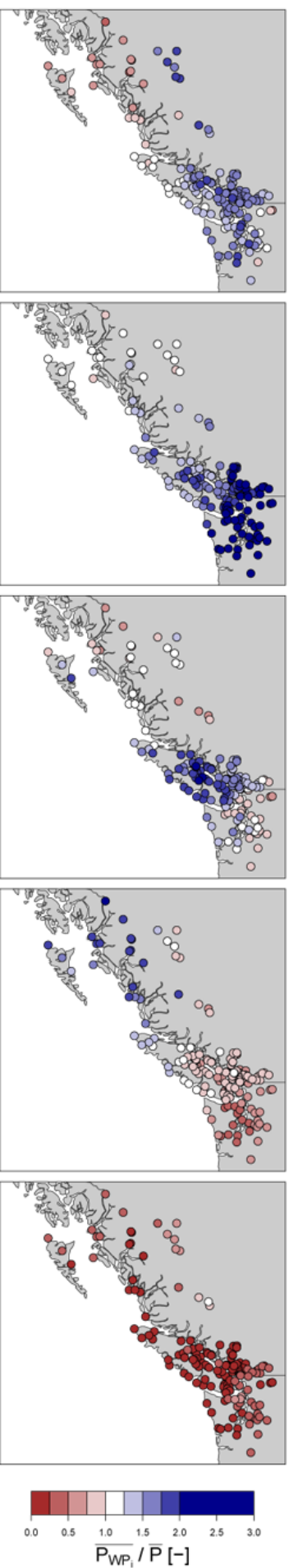

(d)
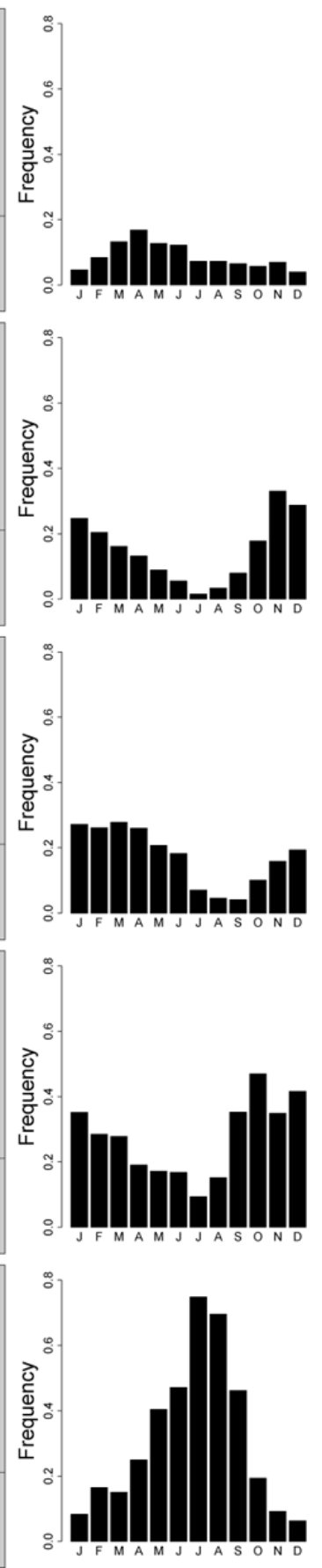

Monthly frequency

Fig. 5. (a) $1000 \mathrm{hPa}$ geopotential height anomaly fields, (b) station mean precipitation amount, (c) station ratio between the mean precipitation amount and the general precipitation amount (considering all WPs) and (d) monthly frequency for each of the five coastal BC WPs, estimated over the 1983-2003 period. Black boxes indicate the spatial coverage of the geopotential space used. 
(a)
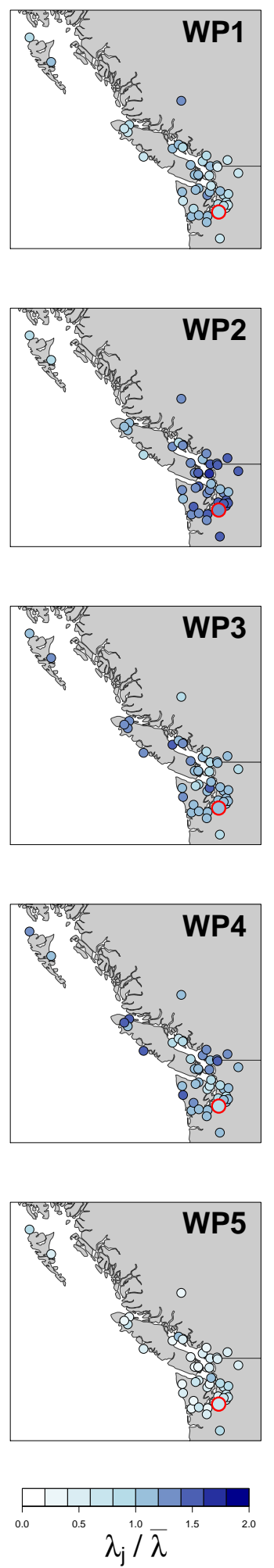

(b)
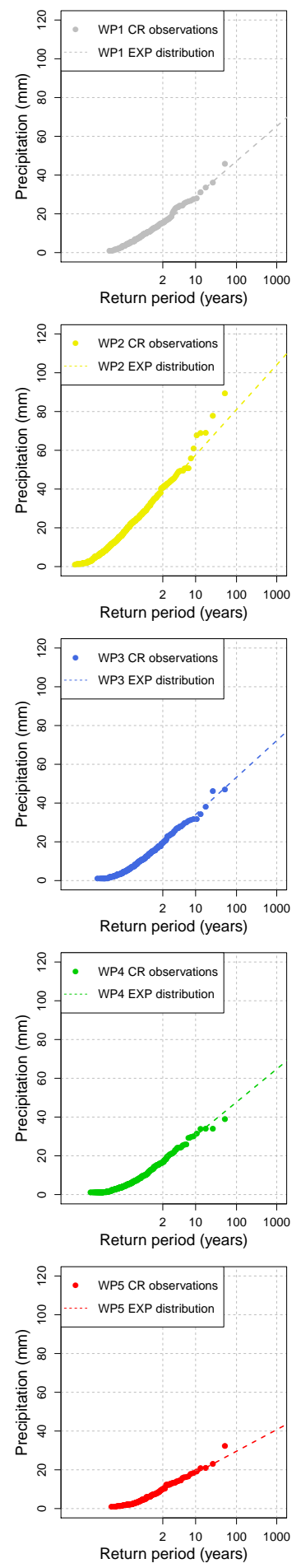

(c)

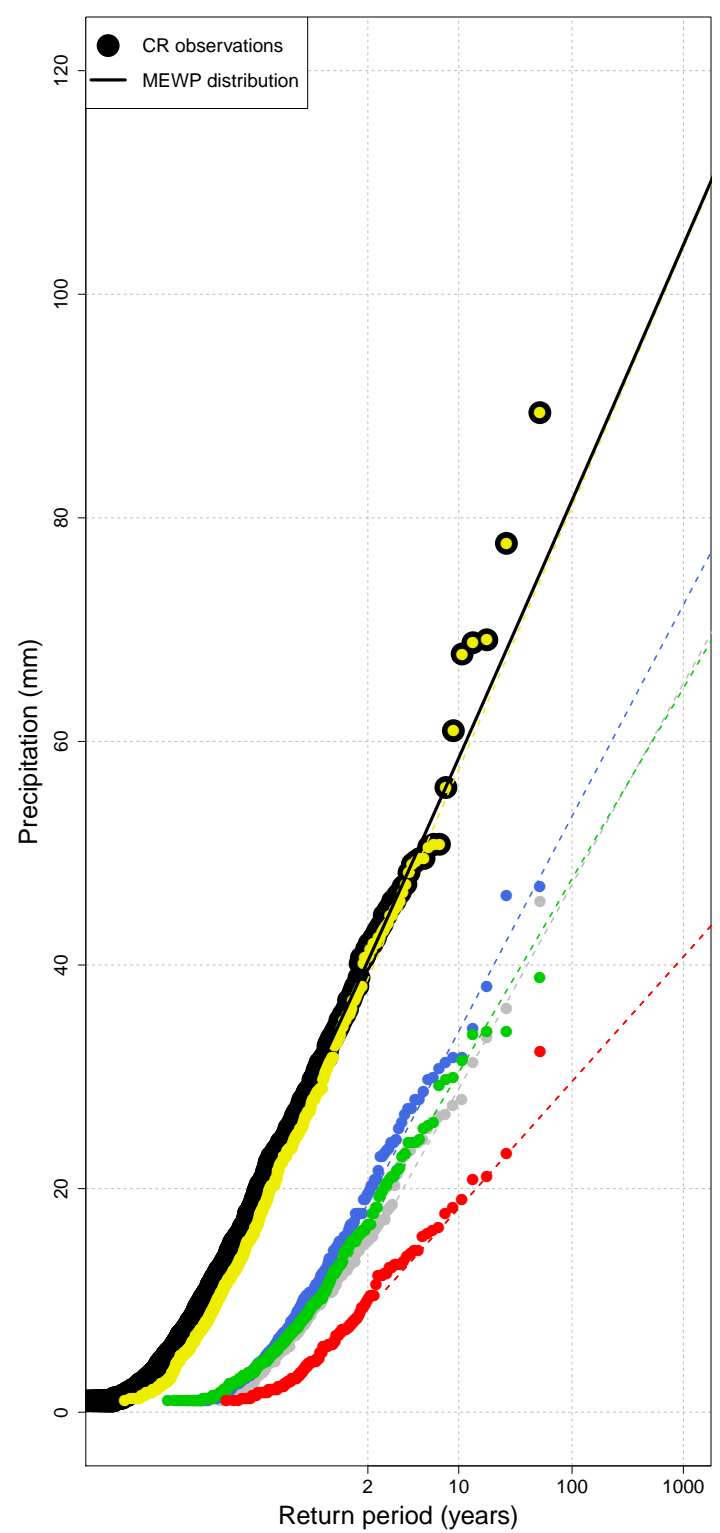

MEWP PARAMETERS

\begin{tabular}{llll} 
WP & $\lambda_{\mathrm{j}}(\mathrm{mm} / 24 \mathrm{~h})$ & $\mathrm{u}_{\mathrm{j}}(\mathrm{mm} / 24 \mathrm{~h})$ & $\mathrm{p}_{\mathrm{j}}(\%)$ \\
\hline WP1 & 7.8 & 16 & 9 \\
WP2 & 10 & 23 & 47 \\
WP3 & 8.2 & 15 & 15 \\
WP4 & 7.4 & 11 & 22 \\
WP5 & 4.8 & 10 & 8
\end{tabular}

Fig. 6. (a) Ratios estimated for 45 rainfall stations and each coastal BC WP between the scale parameter value of the WP considered (parameter $\lambda$ ) and the average value of the five scale parameter values for the station considered. The McMillin reservoir rainfall series is highlighted with a red circle. (b) Five WP sub-samples of the the McMillin reservoir rainfall series and the five exponential distribution fitted on each sub-sample. (c) Final MEWP distribution of the McMillin reservoir rainfall series, which is a combination of the five WP exponential distributions weighted by the CR occurrence of each WP, using Eq. (1). 
empirical winter frequency observed on the 20 Niño winters and 17 Niña winters over the 1951-2001 period (red and blue dots, respectively). In order to characterise the statistical significance of the frequency change between these different year sets, bootstrap simulations were performed. A total of 1000 random combinations of, respectively, 68 and 25 winters among 136 and 50 winters were generated for each period considered. The combinations were made without consideration of the ENSO values and therefore assumed to be representative of climate variability. Frequency changes are assumed to be significant when empirical frequencies are out of the boxplots and thus could not be considered as coming from "natural" climate variability.

Significant but different changes are observed for WP2 and WP3: the WP2 is significantly more common during Niña winters and less common during Niño winters, while the WP3 is significantly more common during Niño winters and less common during Niña winters. Although these changes are statistically significant, the magnitudes of changes are small: WP2 is observed $22 \%$ of all days during Niño winters, whereas it is observed $27 \%$ of days during Niña winters and WP3 is observed $17 \%$ of all days during Niña winters, whereas it is observed $22 \%$ of days during Niño winters. Other tendencies were observed, with the WP1 being more common during Niña winters and less common during Niño winters over the 1871-2007 period, meaning that on average there are more rainy days throughout coastal BC during Niña winters.

This observation is emphasised when the frequency of WPs is estimated on the "extreme ENSO winters". Table 3 shows the coastal BC WP winter (ONDJFM) frequency of 1982-1983 and 1997-1998 Niño winters and of 1973-1974 and 1988-1989 Niña winters. These years are the most severe El Niño and La Niña years observed over the $51 \mathrm{yr}$ (1951-2001) period. The frequency changes observed over all the winters are found again with these winter sub-sets, with WP2, which is clearly more common in La Niña years ( $32 \%$ of all days versus $22 \%$ ) and WP3, which is clearly more common in Niño winters $(37 \%$ of all days versus $17 \%$ ). It also seems that for this set of four "extreme ENSO winters", WP5, which is the anticyclonic one, appears to be less common in Niño winters ( $8 \%$ of all days against $15 \%$ ). This tendency is not clear when we are considering all winter sets in the Fig. 7. The most significant signal is thus a "trade-off" between WP2 and WP3 frequency of occurence.

\subsection{Link between ENSOs and MEWP distributions}

In this section MEWP parameters and distributions are identified on each of the 45 rainfall series, in order to quantify the link between ENSO and MEWP parameters and MEWP distributions. First the MEWP parameters obtained over the whole set of winters are compared with those obtained over the Niño and Niña winter sets. Second, the final MEWP rainfall distributions are compared in order to (a)

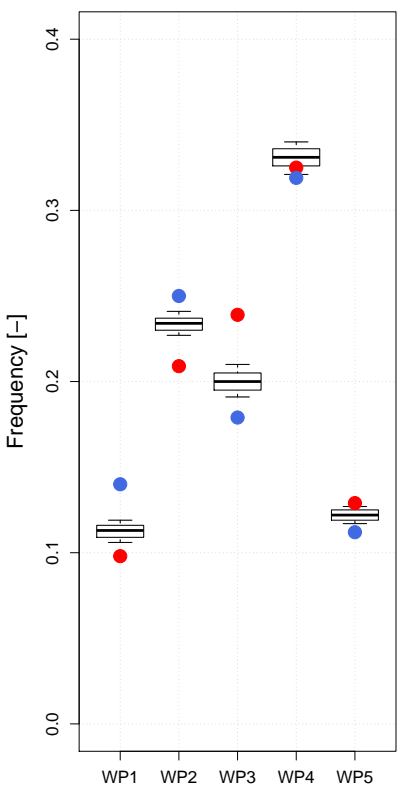

(b)

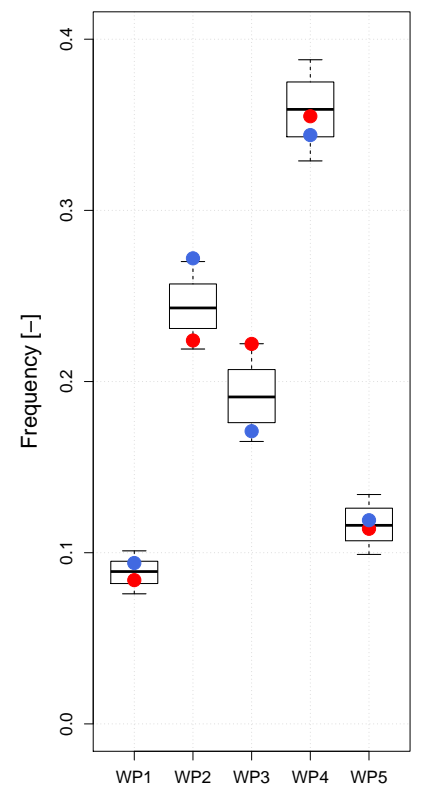

Fig. 7. Winter frequency of the five coastal BC WPs estimated on Niño and Niña winters over (a) the 1871-2008 period and over (b) the 1951-2001 period (plotted with red dots for Niño winters and blue dots for Niña winters); compared with 1000 random combinations of 68 winters out of 137 and 25 winters out of 50 for the 1871-2008 and the 1951-2001 periods, respectively, produced by bootstrap simulations (plotted with boxplots, showing the 0.10 , $0.25,0.50,0.75$ and 0.90 percentiles).

assess the impact of using different parameters on the final MEWP distributions.

Figure 8 compares the MEWP parameters estimated over the 45 analyzed rainfall stations during Niño winters with the MEWP parameters estimated over the 45 analyzed rainfall stations during Niña winters. It is organised as a table, with each column representing one coastal BC WP and each line representing a parameter of the MEWP distributions. Each point represents one of the 45 rainfall series studied. Note that the first two panel rows in Fig. $8(\lambda$ and $u)$ are the parameters of the exponential distribution of each WP, while the third line $(p)$ is the mean number per year of CR events of each WP for each station. Scale parameter value variability (plotted in the first line of the Fig. 8) using different winter sets is significant (from -40 to $+40 \%$ ) but the impact of ENSO on this variability is not straightforward. Variability of the $u$ parameters (plotted in the second line of the Fig. 8) is slightly more limited (from -30 to $+30 \%$ ) but the ENSO impact on their values is also not clear. Nevertheless, WP1 $u$ values (plotted in the second line, first column of the Fig. 8) seem to be significantly higher during Niña winters than during Niño winters. Finally, the variability of CR frequency for each WP (plotted in the third line of the Fig. 8 ) is limited (from -20 to $+20 \%$ ), but ENSOs seem to significantly impact their values: WP1 and WP2 CR events 
Table 3. Average coastal BC WP winter (ONDJFM) frequency of 1982-1983 and 1997-1998 El Niño winters and of 1973-1974 and 19881989 La Niña winters.

\begin{tabular}{ccrrrrrr}
\hline ENSO Winters & & WP1 & WP2 & WP3 & WP4 & WP5 \\
\cline { 1 - 3 } \cline { 6 - 8 } 1982-1983 and 1997-1998 El Niño winters & & $9 \%$ & $22 \%$ & $37 \%$ & $24 \%$ & $8 \%$ \\
$1973-1974$ and 1988-1989 La Niña winters & & $10 \%$ & $32 \%$ & $17 \%$ & $26 \%$ & $15 \%$ \\
\hline
\end{tabular}
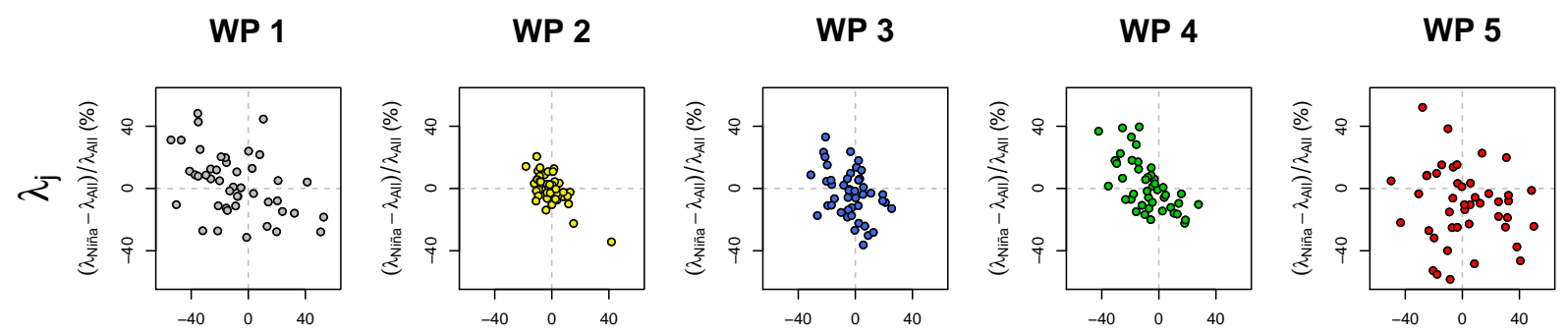

$\left(\lambda_{\text {Niño }}-\lambda_{\text {All }}\right) / \lambda_{\text {All }}(\%)$
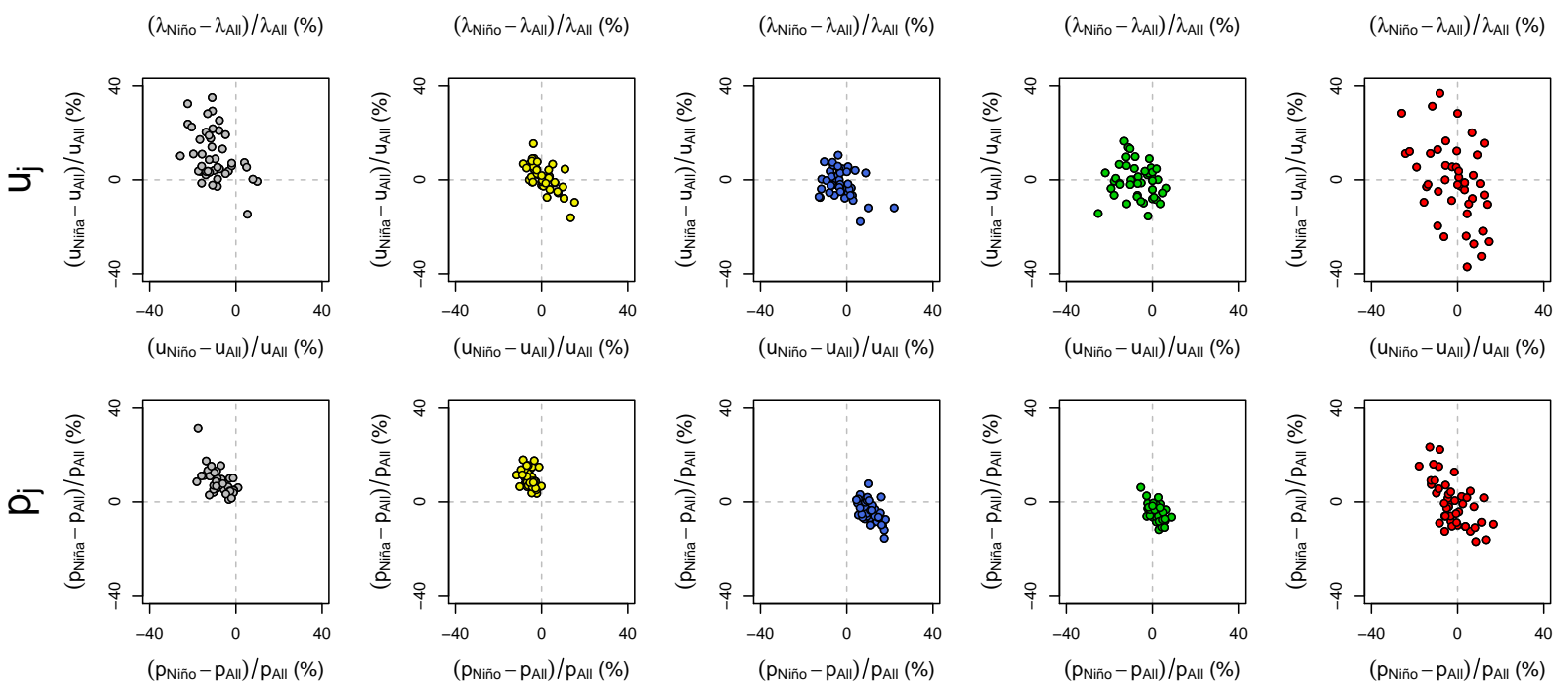

Fig. 8. Comparison of the MEWP distribution parameters obtained over all winter sets and 20 Niño winters (x-axis) and over all winter sets and 17 Niña winters (y-axis) for each the 45 stations and for each of the five coastal BC WPs.

are more frequent during Niña winters (plotted in the second line, first and second columns of the Fig. 8, respectively), while WP3 and WP4 CR events appear to be more frequent during Niño winters (plotted in the second line, third and fourth columns of the Fig. 8, respectively), as shown for WP frequency in Sect. 4.4. It is important to note that MEWP parameters are strongly not independent: for a given rainfall station and a given WP, the scale parameter values are totally dependent on the quantile threshold values considered for the definition of the heavy rainfall events sub-population (the 0.80 quantile in this study).

The estimations of $1000 \mathrm{yr}$ return period precipitation values (noted $P_{1000}$ hereafter, expressed in $\mathrm{mm}$ ) were then compared. First, three MEWP distributions were defined for each of the 45 precipitation series: one considering all 50 winters, one considering 20 Niño winters and one considering 17 Niña winters and thus using the MEWP parameters illustrated in Fig. 8. A bootstrap test was then performed for each of the 45 stations in order to test the significance of eventual changes between heavy rainfall estimation over Niño winters and heavy rainfall estimation over Niña winters.

First, the difference between Niño and Niña winter heavy precipitation estimations is illustrated through the McMillin reservoir precipitation series on Fig. 9a for Niño winter observations and estimations and on Fig. 9b for Niña winter observations and estimations. The grey envelopes corresponds to the $90 \%$ confidence interval (CI) estimated with the bootstrap simulations. For the McMillin reservoir precipitation series, heavy rainfall estimations performed using the Niño winter sets are lower than heavy rainfall estimations performed using all winter sets and the Niña winter sets. Nevertheless, the estimations performed using the Niño winter sets and the Niña winter sets are in the $90 \%$ CI generated through the bootstrap simulations.

Differences between the different heavy rainfall estimations were then examined at the regional scale. The result of 
(a)

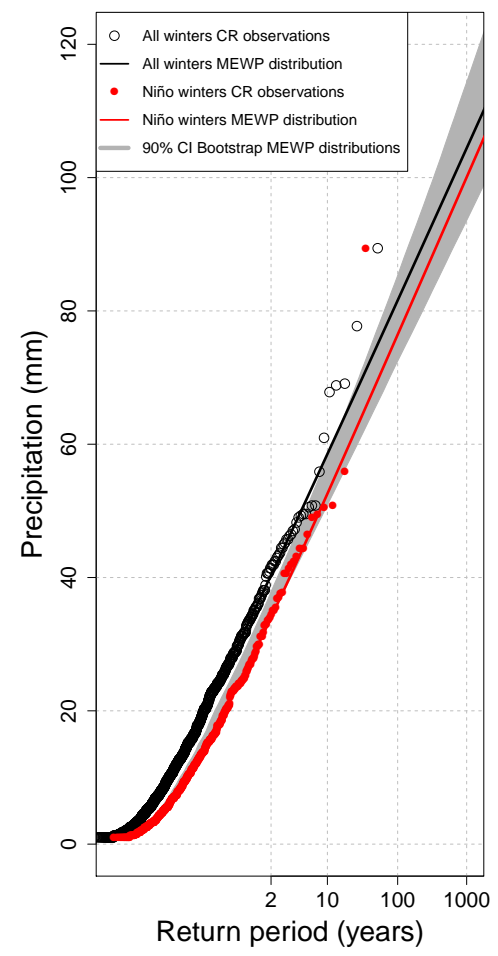

MEWP PARAMETERS

\begin{tabular}{llll} 
WP & $\lambda_{\mathrm{j}}(\mathrm{mm} / 24 \mathrm{~h})$ & $\mathrm{u}_{\mathrm{j}}(\mathrm{mm} / 24 \mathrm{~h})$ & $\mathrm{p}_{\mathrm{j}}(\%)$ \\
\hline WP1 & 4.5 & 12 & 9 \\
WP2 & 10.3 & 23 & 43 \\
WP3 & 6.2 & 13 & 19 \\
WP4 & 6.3 & 10 & 22 \\
WP5 & 3.8 & 12 & 7 \\
WP1 & 7.8 & 16 & 9 \\
WP2 & 10 & 23 & 47 \\
WP3 & 8.2 & 15 & 15 \\
WP4 & 7.4 & 11 & 22 \\
WP5 & 4.8 & 10 & 8
\end{tabular}

(b)

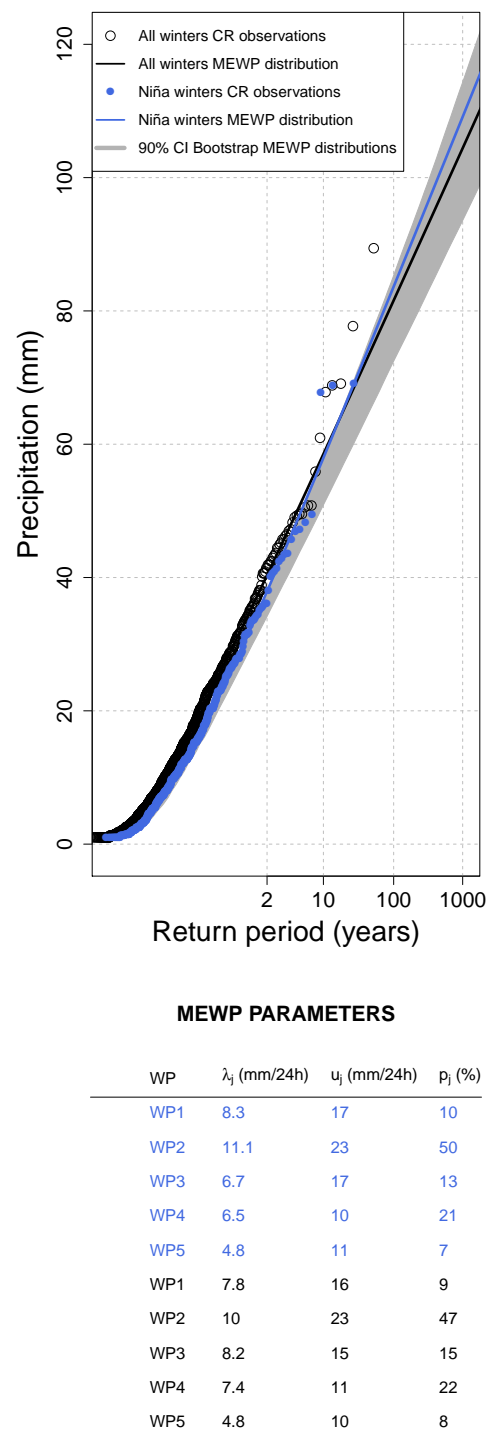

Fig. 9. MEWP distributions for the winter season (ONDJFM) defined over (a) all winter sets (black line), Niño winters (red line) and 1000 random combinations of 25 winters (grey envelopes) and defined over (b) all winter sets (black line), Niña winters (blue line) and 1000 random combinations of 25 winters (grey envelopes) for the McMillin reservoir rainfall series.

a significance test is plotted in Fig. 10, which represents the degree of significance between $P_{1000}$ values defined on Niño winters or on Niña winters for each of the 45 stations. The colour assigned to each rainfall station represents where are the $P_{1000}$ values estimated using Niño winters as inputs of the MEWP model (Fig. 10a) and the $P_{1000}$ values estimated using Niña winters as inputs of the MEWP model (Fig. 10b) within the distribution of $1000 P_{1000}$ values estimated using 1000 random winter combinations, for each of the 45 rainfall stations. A station plotted with a green colour means that the $P_{1000 \text { Niño }}$ or the $P_{1000}$ Niña values are lower than the 0.05 quantile of the $1000 P_{1000}$ values, while a station plotted with a purple colour means that $P_{1000 \text { Niño }}$ or $P_{1000 \text { Niña values are }}$ greater than the 0.95 quantile of the $1000 P_{1000}$ values. Thus, green colour and purple colour highlight the stations where $P_{1000}$ values estimated on particular winter set are significantly different from the total $P_{1000}$ distribution. Some interesting local behaviours are detected: for example, northern stations seem to be characterised by $P_{1000}$ values greater during Niña winters and, on the contrary, $P_{1000}$ values are lower during Niño winters. Nevertheless, none regional tendency is observed over the 45 coastal BC station considered.

\section{Conclusions}

A WP classification has been defined on the coastal $\mathrm{BC}$ region using 177 rainfall stations and geopotential height fields 
(a)

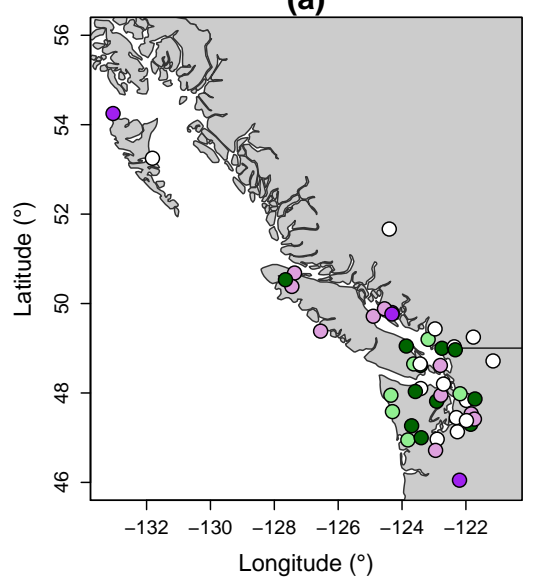

(b)

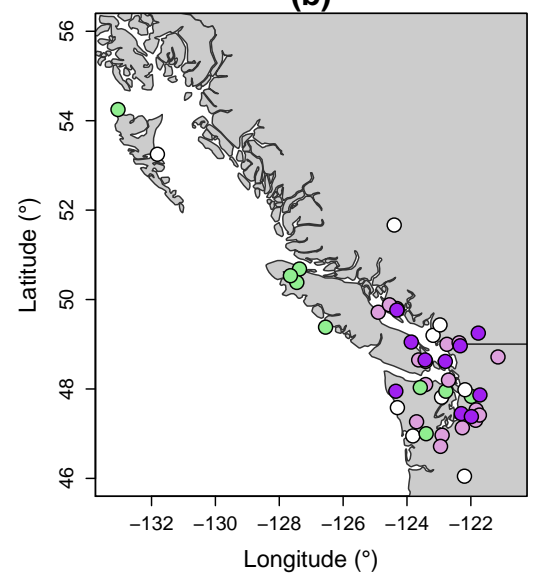

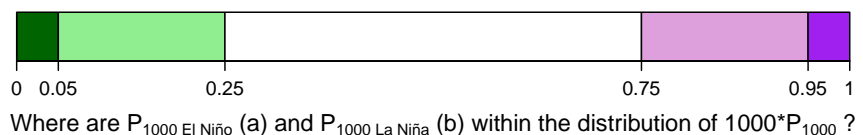

Fig. 10. Degree of significance between $P_{1000}$ values estimated by MEWP distributions defined over 20 Niño winters or on 17 Niña winters for each of the 45 stations and $P_{1000}$ values estimated by MEWP distributions defined over random combination of 25 winter precipitation observations generated by bootstrap simulations.

over a larger area in order to analyse winter heavy rainfall events in this region. Five contrasted WPs composed this classification, four rainy WPs and one non-rainy WP, the anticyclonic pattern. The four rainy WPs are mainly observed in the winter months (October to March), which is the period of heavy precipitation events in coastal $\mathrm{BC}$ and is thus consistent with the local climatology. The combination of this WP classification with the seasonal description of rainfall is shown to be useful for splitting observed precipitation series into more homogeneous sub-samples and thus identifying for each station the synoptic situations that generate the highest hazard in terms of heavy rainfall events. Thus, in this area of coastal $\mathrm{BC}$, the highest heavy rainfall hazard is mainly generated by WP2 for the major part of the northwestern Washington region and Vancouver City region, by WP3 for Vancouver Island area and by WP4 for the northern coastal BC region.

El Niño-Southern Oscillations influence significantly the frequency of occurrence of two coastal BC WPs: WP2 is more common during Niña winters rather than during Niño winters and WP3 is clearly more common during Niño winters than during Niña winters. These changes are statistically significant, but the magnitudes of changes are small: WP2 is observed $22 \%$ of all days during Niño winters, whereas it is observed $27 \%$ of days during Niña winters, and WP3 is observed $17 \%$ of all days during Niña winters, whereas it is observed $22 \%$ of days during Niño winters. These results are consistent with findings of Casola and Wallace (2007), who showed that ENSO significantly influences the frequency of their four weather regimes defined over the Pacific-North American Sector with winter $500 \mathrm{hPa}$ geopo- tential height fields. Empirical evidence of ENSO influence on rainfall characteristic has been observed. Significant differences are observed in terms of average winter amount of rain over coastal BC, with about $+8 \%$ rain during Niña winters compared to all winters on average over the 45 stations considered, and $-8 \%$ rain during Niño winters compared to all winters on average over the 45 stations considered. A lower frequency of heavy rainfall events (here defined as days with $20 \mathrm{~mm}$ or more observed) during Niño winters compared to all the winters for the 45 considered stations seems to be observed. Finally, heavy (percentile 0.70) and extreme empirical quantiles (percentile 0.95) seems to be slightly lower during Niño winters compared to all winters and slightly higher during Niña winters compared to all winters. Within each WP, ENSOs seem to only influence the frequency of rainy events and not the magnitude of heavy rainfall events: WP1 and WP2 central rainfall events are more frequent during Niña winters, while WP3 and WP4 central rainfall events appear to be more frequent during Niño winters. MEWP heavy rainfall estimations do not show significant evolution of heavy rainfall behaviour between Niño and Niña winters: ENSO is not influencing significantly the $1000 \mathrm{yr}$ return period precipitation values estimated over the coastal BC region through the MEWP rainfall probabilistic model. Natural variability seems thus to be predominantly explaining the differences of heavy rainfall values estimated through the MEWP rainfall probabilistic model over coastal $\mathrm{BC}$ region. These results are consistent with the findings of Feldl and Roe (2011) which showed that ENSO could influence differently mean rainfall values and the extreme rainfall quantiles and with studies that did not find a significant 
influence of ENSO on extreme rainfall values over coastal BC region (e.g. Kenyon and Hegerl, 2010 and Zhang et al., 2011).

The main difference between Niño and Niña winter precipitation is thus found in the frequency of rainy events and in the mean annual amounts of precipitation, probably explaining the differences observed in the hydrological cycle (snowfall amount, flood magnitudes, etc.) previously highlighted in the literature. Thus, many "small" and "average" rainy events during a Niña winter will saturate watersheds and increase snowpack, which could produce heavy floods even from these "small" or "average" rainy events compared to a Niño winter when even a heavy rainfall storm could fall on dry soil or on below-average snowpack and result in a insignificant flood event. These hypotheses could be tested in future studies by applying methods for extreme flood estimation such as the SCHADEX method (Paquet et al., 2006) on coastal BC catchments with the same methodology: comparing flood estimations made using all available winters with estimations made using only Niña winters, only Niño winters, and using randomly associated winter sub-sets.

Future investigations could focus on other climate signals relevant for the region such as the Pacific Decadal Oscillation (PDO), an oscillation which has a significant impact on hydro-climatology in Western Canada (see Whitfield et al., 2010 for a review). Combinations of different climate signals with different oscillation periods could also be important to consider.

Finally, these results open interesting perspectives in the fields of climate change impact prediction on heavy rainfall distribution, where WP classifications could be "mediumscale disaggregating tools" between General Circulation Model outputs and local rainfall observations.

Acknowledgements. The authors thank the two reviewers who provided constructive comments on an earlier version of the manuscript, which helped clarify the text. Douglas McCollor and Gregory West from BC Hydro are thanked for interesting discussions on BC WPs. Our thanks are extended to Mel Schaefer from MGS Engineering Consultants, Inc. for providing the Washington State precipitation series. This work has been done in the framework of a collaboration project between EDF and BC Hydro on comparison of flood estimation methods.

Edited by: R. Uijlenhoet

\section{References}

Allamano, P., Laio, F., and Claps, P.: Effects of disregarding seasonality on the distribution of hydrological extremes, Hydrol. Earth Syst. Sci., 15, 3207-3215, doi:10.5194/hess-15-32072011, 2011.

Ansell, T. J., Jones, P. D., Allan, R. J., Lister, D., Parker, D. E., Brunet, M., Moberg, A., Jacobeit, J., Brohan, P., Rayner, N. A., Aguilar, E., Alexandersson, H., Barriendos, M., Brandsma, T.,
Cox, N. J., Della-Marta, P. M., Drebs, A., Founda, D., Gerstengarbe, F., Hickey, K., Jónsson, T., Luterbacher, J., Nordli, $\emptyset .$, Oesterle, H., Petrakis, M., Philipp, A., Rodwell, M. J., Saladie, O., Sigro, J., Slonosky, V., Srnec, L., Swail, V., GarcíaSuárez, A. M., Tuomenvirta, H., Wang, X., Wanner, H., Werner, P., Wheeler, D., and Xoplaki, E.: Daily Mean Sea Level Pressure Reconstructions for the European-North Atlantic Region for the Period 1850-2003, J. Climate, 19, 2717-2742, doi:10.1175/JCLI3775.1, 2006.

Beaulant, A.-L., Joly, B., Nuissier, O., Somot, S., Ducrocq, V., Joly, A., Sevault, F., Deque, M., and Ricard, D.: Statistico-dynamical downscaling for Mediterranean heavy precipitation, Q. J. Roy. Meteor. Soc., 137, 736-748, doi:10.1002/qj.796, 2011.

Boé, J. and Terray, L.: A Weather-Type Approach to Analyzing Winter Precipitation in France: Twentieth-Century Trends and the Role of Anthropogenic Forcing, J. Climate, 21, 3118-3133, doi:10.1175/2007JCLI1796.1, 2008.

Bontron, G.: Prévision quantitative des précipitations: adaptation probabiliste par recherche d'analogues. Utilisation des réanalyses NCEP/NCAR et application aux précipitations du SudEst de la France, Ph.D. Thesis, Institut Polytechnique de Grenoble, 2004.

Brigode, P., Bernardara, P., Gailhard, J., Garavaglia, F., Ribstein, P., and Merz, R.: Optimization of the geopotential heights information used in a rainfall-based weather patterns classification over Austria, International J. Climatol., 8, 1563-1573, doi:10.1002/joc.3535, 2013.

Casola, J. H. and Wallace, J. M.: Identifying Weather Regimes in the Wintertime 500-hPa Geopotential Height Field for the Pacific-North American Sector Using a Limited-Contour Clustering Technique, J. Appl. Meteorol. Clim., 46, 1619-1630, doi:10.1175/JAM2564.1, 2007.

Cayan, D. R., Redmond, K. T., and Riddle, L. G.: ENSO and Hydrologic Extremes in the Western United States, J. Climate, 12, 2881-2893, doi:10.1175/15200442(1999)012;2881:EAHEIT;2.0.CO;2, 1999.

Chen, W. Y. and van den Dool, H. M.: Significant change of extratropical natural variability and potential predictability associated with the El Niño/Southern Oscillation, Tellus A, 51, 790-802, doi:10.1034/j.1600-0870.1999.00017.x, 1999.

Cheng, X. and Wallace, J. M.: Cluster Analysis of the Northern Hemisphere Wintertime 500-hPa Height Field: Spatial Patterns, Journal of Atmospheric Sciences, 50, 2674-2696, doi:10.1175/1520-0469(1993)050;2674:CAOTNH $; 2.0 . C O ; 2$, 1993.

Coles, S., Pericchi, L. R., and Sisson, S.: A fully probabilistic approach to extreme rainfall modeling, J. Hydrol., 273, 35-50, doi:10.1016/S0022-1694(02)00353-0, 2003.

Compo, G. P., Whitaker, J. S., Sardeshmukh, P. D., Matsui, N., Allan, R. J., Yin, X., Gleason, B. E., Vose, R. S., Rutledge, G., Bessemoulin, P., Brönnimann, S., Brunet, M., Crouthamel, R. I., Grant, A. N., Groisman, P. Y., Jones, P. D., Kruk, M. C., Kruger, A. C., Marshall, G. J., Maugeri, M., Mok, H. Y., Nordli, Ø., Ross, T. F., Trigo, R. M., Wang, X. L., Woodruff, S. D., and Worley, S. J.: The Twentieth Century Reanalysis Project, Q. J. Roy. Meteor. Soc., 137, 1-28, doi:10.1002/qj.776, 2011.

Dettinger, M.: Fifty-Two Years of "Pineapple-Express" Storms across the West Coast of North America, Tech. Rep. CEC500-2005-004, US Geological Survey, Scripps Institution of 
Oceanography for the California Energy Commission, PIER Energy-Related Environmental Research, 2004.

Djerboua, A. and Lang, M.: Scale parameter of maximal rainfall distribution: comparison of three sampling techniques, Revue des Sciences de l'Eau, 20, 2007.

Ducić, V., Luković, J., Burić, D., Stanojević, G., and Mustafić, S.: Precipitation extremes in the wettest Mediterranean region (Krivošije) and associated atmospheric circulation types, Nat. Hazards Earth Syst. Sci., 12, 687-697, doi:10.5194/nhess-12687-2012, 2012.

Efron, B.: Bootstrap Methods: Another Look at the Jackknife, The Annals of Statistics, 7, 1-26, doi:10.1214/aos/1176344552, 1979.

Feldl, N. and Roe, G. H.: Climate Variability and the Shape of Daily Precipitation: A Case Study of ENSO and the American West, J. Climate, 24, 2483-2499, doi:10.1175/2010JCLI3555.1, 2011.

Fernández-González, S., del Río, S., Castro, A., Penas, A., Fernández-Raga, M., Calvo, A. I., and Fraile, R.: Connection between NAO, weather types and precipitation in León, Spain (1948-2008), Int. J. Climatol., doi:10.1002/joc.2431, 2011.

Fréchet, M.: Sur la loi de probabilité de l'écart maximum, Annales de la Société Polonaise de Mathématiques, 6, 92-116, 1927.

Garavaglia, F., Gailhard, J., Paquet, E., Lang, M., Garçon, R., and Bernardara, P.: Introducing a rainfall compound distribution model based on weather patterns sub-sampling, Hydrol. Earth Syst. Sci., 14, 951-964, doi:10.5194/hess-14-951-2010, 2010.

Garavaglia, F., Lang, M., Paquet, E., Gailhard, J., Garçon, R., and Renard, B.: Reliability and robustness of rainfall compound distribution model based on weather pattern sub-sampling, Hydrol. Earth Syst. Sci., 15, 519-532, doi:10.5194/hess-15-519-2011, 2011.

Gershunov, A.: ENSO Influence on Intraseasonal Extreme Rainfall and Temperature Frequencies in the Contiguous United States: Implications for Long-Range Predictability, J. Climate, 11, 3192-3203, doi:10.1175/15200442(1998)011;3192:EIOIER ¿2.0.CO;2, 1998.

Guilbaud, S. and Obled, C.: Daily quantitative precipitation forecast by an analogue technique: optimisation of the analogy criterion, Comptes Rendus de l'Académie des Sciences - Series IIA. Earth Planet. Sci., 327, 181-188, doi:10.1016/S1251-8050(98)800062, 1998.

Gumbel, E. J.: Statistics of Extremes, New York, columbia university press edn., 1958.

Higgins, R., Schemm, J., Shi, W., and Leetmaa, A.: Extreme precipitation events in the western United States related to tropical forcing, J. Climate, 13, 793-820, 2000.

Jarvis, A., Reuter, H. I., Nelson, A., and Guevara, E.: Hole-filled SRTM for the globe Version 4, available from the CGIAR-CSI SRTM 90 m Database (available at: http://www.cgiar-csi.org/ 2010/03/108/), 2008.

Kenyon, J. and Hegerl, G. C.: Influence of Modes of Climate Variability on Global Precipitation Extremes, J. Climate, 23, 62486262, doi:10.1175/2010JCLI3617.1, 2010.

Kimoto, M. and Ghil, M.: Multiple flow regimes in the Northern Hemisphere winter. Part II: Sectorial regimes and preferred transitions, J. Atmos. Sci., 50, 2645-2673, 1993.

Littmann, T.: An empirical classification of weather types in the Mediterranean Basin and their interrelation with rainfall, Theor. Appl. Climatol., 66, 161-171, doi:10.1007/s007040070022,
2000.

Mass, C., Skalenakis, A., and Warner, M.: Extreme Precipitation over the West Coast of North America: Is There a Trend?, J. Hydrometeorol., 12, 310-318, doi:10.1175/2010JHM1341.1, 2011.

McCabe, G. and Muller, R.: Effects of ENSO on weather-type frequencies and properties at New Orleans, Louisiana, USA, Clim. Res., 20, 95-105, 2002.

Mezghani, A. and Hingray, B.: A combined downscalingdisaggregation weather generator for stochastic generation of multisite hourly weather variables over complex terrain: Development and multi-scale validation for the Upper Rhone River basin, J. Hydrol., 377, 245-260, doi:10.1016/j.jhydrol.2009.08.033, 2009.

Neiman, P. J., Schick, L. J., Ralph, F. M., Hughes, M., and Wick, G. A.: Flooding in Western Washington: The Connection to Atmospheric Rivers, J. Hydrometeorol., 12, 1337-1358, doi:10.1175/2011JHM1358.1, 2011.

Obled, C., Bontron, G., and Garçon, R.: Quantitative precipitation forecasts: a statistical adaptation of model outputs through an analogues sorting approach, Atmos. Res., 63, 303-324, doi:10.1016/S0169-8095(02)00038-8, 2002.

Pague, B. S. and Blandford, S. M.: Weather types, in: Weather Forecasting and Weather Types on the North Pacific Slope, Weather Bureau Print, 20-29, 1897.

Paquet, E., Gailhard, J., and Garçon, R.: Evolution of the GRADEX method : improvement by atmospheric circulation classification and hydrological modelling, La Houille Blanche, 80-90, doi:10.1051/lhb:2006091, 2006.

Pickands, J. P.: Statistical Inference Using Extreme Order Statistics, The Annals of Statistics, 3, 119-131, doi:10.1214/aos/1176343003, 1975.

Robertson, A. W. and Ghil, M.: Large-Scale Weather Regimes and Local Climate over the Western United States, J. Climate, 12, 1796-1813, doi:10.1175/15200442(1999)012;1796:LSWRAL ¿2.0.CO;2, 1999.

Schubert, S. D., Chang, Y., Suarez, M. J., and Pegion, P. J.: ENSO and Wintertime Extreme Precipitation Events over the Contiguous United States, J. Climate, 21, 22-39, doi:10.1175/2007JCLI1705.1, 2008.

Shabbar, A., Bonsal, B., and Khandekar, M.: Canadian Precipitation Patterns Associated with the Southern Oscillation, J. Climate, 10, 3016-3027, doi:10.1175/15200442(1997)010;3016:CPPAWT ¿2.0.CO;2, 1997.

Sheridan, S. C.: The redevelopment of a weather-type classification scheme for North America, Int. J. Climatol., 22, 51-68, doi:10.1002/joc.709, 2002.

Stahl, K., Moore, R. D., and Mckendry, I. G.: The role of synoptic-scale circulation in the linkage between largescale ocean-atmosphere indices and winter surface climate in British Columbia, Canada, Int. J. Climatol., 26, 541-560, doi:10.1002/joc.1268, 2006.

Teweles, J. and Wobus, H.: Verification of prognosis charts, B. Am. Meteorol. Soc., 35, 455-463, 1954.

Trenberth, K.: The definition of El Niño, B. Am. Meteorol. Soc., 78, 2771-2778, 1997.

Ward, J. H.: Hierarchical grouping to optimize an objective function, J. Am. Stat. Assoc., 58, 236-244, doi:10.2307/2282967, 1963. 
Whitfield, P. H., Moore, R. D., Fleming, S. W., and Zawadzki, A.: Pacific Decadal Oscillation and the Hydroclimatology of Western Canada - Review and Prospects, Can. Water Resour. J., 35, 1-28, doi:10.4296/cwrj3501001, 2010.

Yarnal, B. and Diaz, H. F.: Relationships between extremes of the Southern oscillation and the winter climate of the Anglo-American Pacific Coast, J. Climatol., 6, 197-219, doi:10.1002/joc.3370060208, 1986.
Zhang, X., Wang, J., Zwiers, F. W., and Groisman, P. Y.: The Influence of Large-Scale Climate Variability on Winter Maximum Daily Precipitation over North America, J. Climate, 23, 2902 2915, doi:10.1175/2010JCLI3249.1, 2010.

Zhang, Y., Qian, Y., Dulière, V., Salathé, E. P., and Leung, L. R.: ENSO anomalies over the Western United States: present and future patterns in regional climate simulations, Climatic Change, doi:10.1007/s10584-011-0088-7, 2011. 